\title{
Early Predictors of Reading Comprehension Difficulties
}

\author{
Åsa Elwér
}

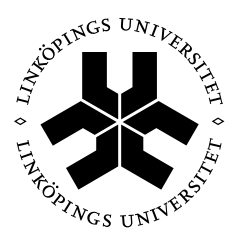

\section{Linköping University}

Linköping Studies in Behavioural Science No. 186 Linköping University

Department of Behavioural Sciences and Learning Linköping 2014 
Linköping Studies in Behavioural Science $•$ No. 186

Distributed by:

Department of Behavioural Sciences and Learning

Linköping University

SE - 58183 Linköping

Åsa Elwér

Early predictors of reading comprehension difficulties

Edition 1:1

ISBN 978-91-7519-281-9

ISSN 1654-2029

(C)Author

Department of Behavioural Sciences and Learning, 2014

Printed by: LiU-tryck, Linköping 2014 


\section{Content}

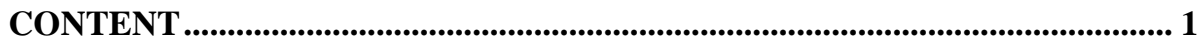

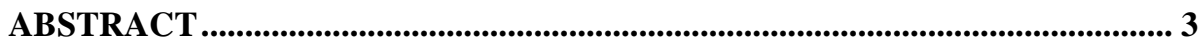

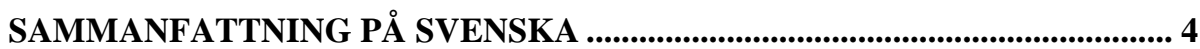

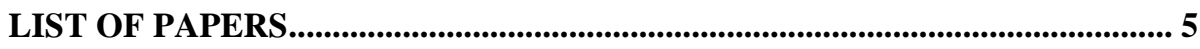

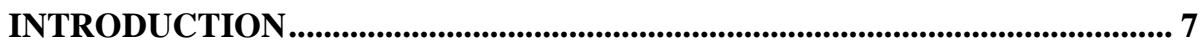

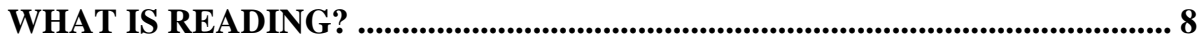

WORD READING ........................................................................................... 9

PHASES OF DECODING DEVELOPMENT ........................................................... 10

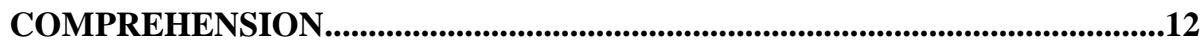

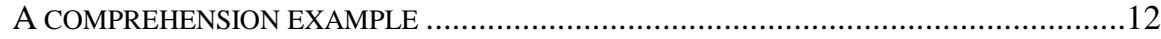

DIFFERENT TYPES OF COMPREHENSION .......................................................... 13

A COMPREHENSION MODEL ........................................................................... 15

ASSESSMENT OF READING COMPREHENSION ..................................................17

EARLY PREDICTORS OF READING ......................................................19

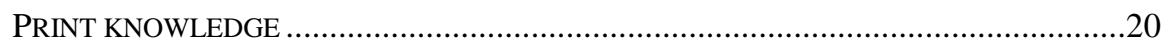

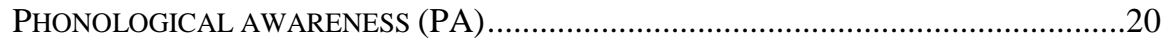

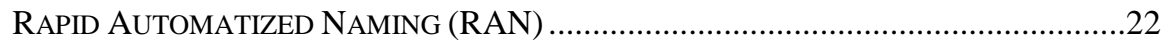

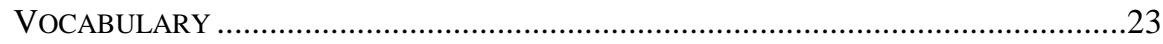

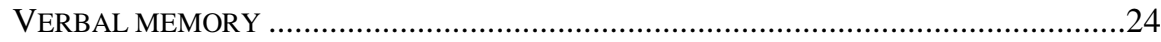

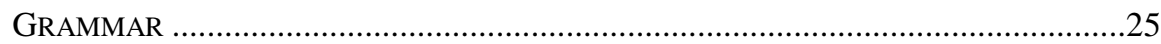

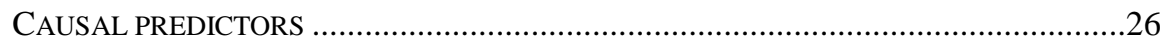

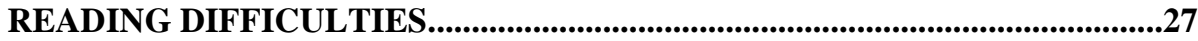

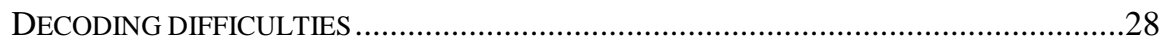

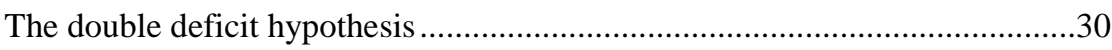

Decoding deficits and reading comprehension ...............................................31

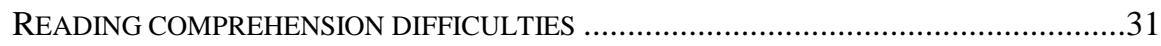




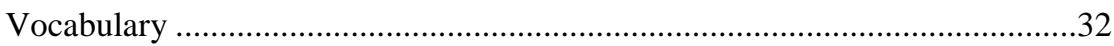

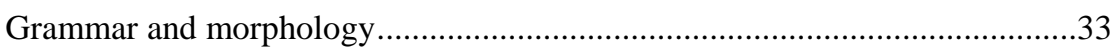

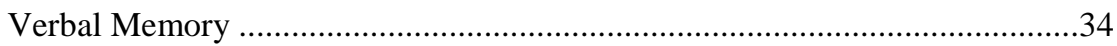

Inferences and other text-related processes .......................................................35

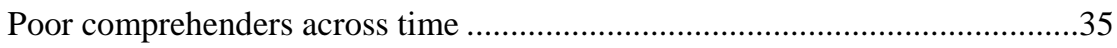

Within-group variability and interventions....................................................36

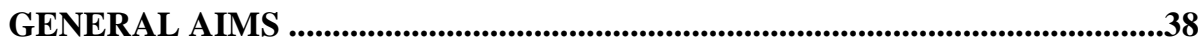

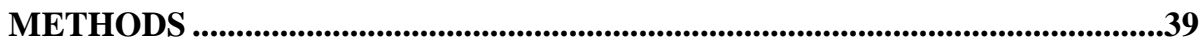

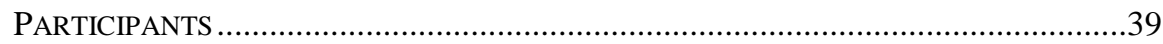

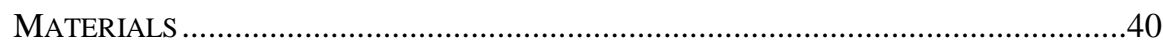

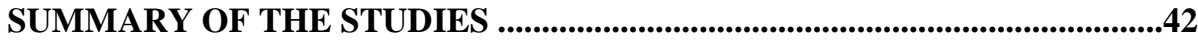

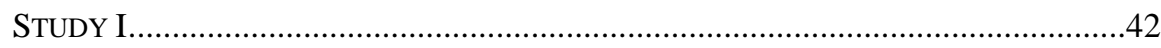

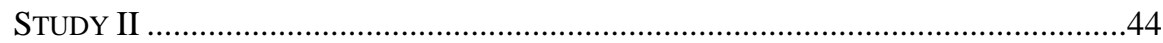

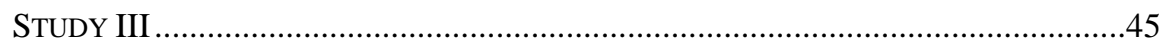

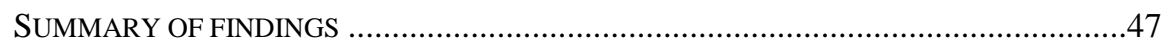

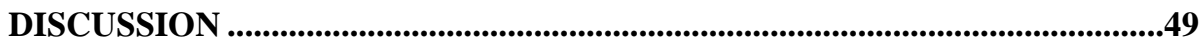

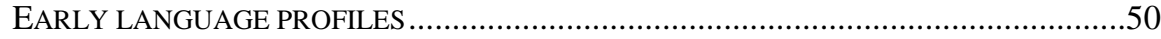

DEFICITS IN READING COMPREHENSION ……..................................................52

METHODOLOGICAL LIMITATIONS .....................................................................54

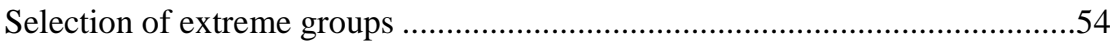

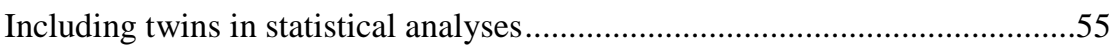

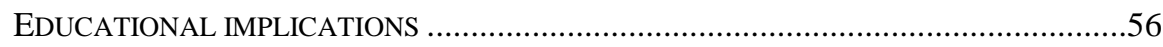

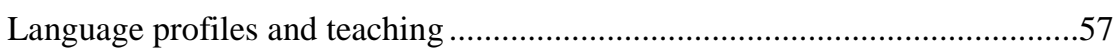

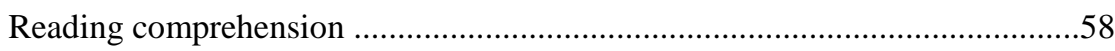

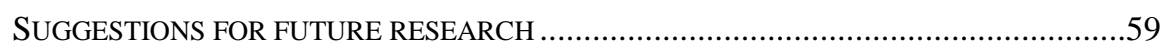

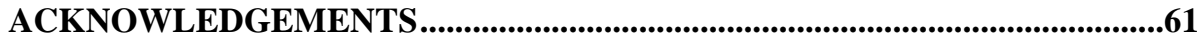

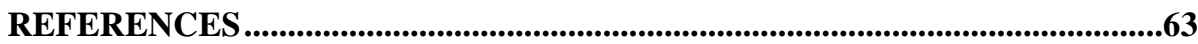




\section{Abstract}

The aim of the present thesis was to examine the cognitive and language profile in children with poor reading comprehension using a longitudinal perspective. Even though comprehension skills are closely connected to educational success, comprehension deficits in children have been neglected in reading research. Understanding factors underlying reading is important as it improves possibilities of early identification of children at risk of developing reading problems. In addition, targeted interventions may prevent or reduce future problems. Descriptions of the cognitive and language profile in children with different types of reading problems from an early age and over time is an important first step.

The three studies included in this thesis have been conducted using data from the International Longitudinal Twin Study (ILTS). In the ILTS, parallel data have been collected in the US, Australia, Sweden and Norway. Altogether, more than 1000 twin pairs have been examined between the ages 5 and 15 years using well known predictors of reading, along with decoding, spelling, reading comprehension and oral language measures.

In the three studies, the Simple View of Reading has been used as a theoretical framework and children who exhibited different kinds of comprehension-related difficulties have been identified at different ages. The studies include both retrospective and prospective analyses. The results across studies indicated a robust oral language deficit in all subtypes displaying comprehension problems. The oral language deficit was widespread and included vocabulary, grammar and verbal memory. In addition, the oral language deficit was manifested as compromised phonological awareness and print knowledge prior to reading instruction. Reading comprehension deficits were late emerging across studies in children with comprehension difficulties. 


\section{Sammanfattning på svenska}

Syftet med avhandlingen har varit att undersöka den kognitiva och språkliga profilen hos barn med läsförståelseproblem $i$ ett longitudinellt perspektiv. Förståelserelaterade problem är eftersatt del av läsforskningen, trots att denna typ av svårigheter har visat sig få stora konsekvenser för fortsatt framgång i skolan. Att förstå underliggande faktorer när det gäller läsning är viktigt för att kunna identifiera barn tidigt $\mathrm{i}$ utvecklingen och anpassa undervisningen efter deras behov. Att beskriva barnens kognitiva och språkliga profil från tidig ålder och över tid är ett viktigt första steg i detta arbete.

De tre studierna som ingår i avhandlingen har baserats på data från the International Longitudinal Twin Study (ILTS). I projektet har data samlats in i USA, Australien, Sverige och Norge. Sammanlagt har mer än 1000 tvillingpar testas vid upprepade tillfällen i åldersspannet 5 till 15 år. Testmaterialet innefattar ett stort batteri av språkliga och kognitiva tester, samt tester i läsning och stavning.

Med utgångspunk $\mathrm{i}$ the Simple View of Reading har grupper av barn med olika typer av förståelseproblem identifierats vid olika tidpunkter i utvecklingen. Studierna innehåller både retrospektiva och prospektiva analyser. Resultaten visar en tydligt bred språklig nedsättning hos barnen med förståelserelaterade problem som visar sig tydligt i mätningar av ordförråd, grammatik och verbalt minne. Problemen är stabila över tid och visar sig tidigt i utvecklingen även som fonologiska svårigheter. Svag språklig profil påverkar inte läsförståelse förrän barnen gått i skolan ett antal år. 


\section{List of papers}

I Elwér, Å., Keenan, J. M., Olson, R. K., Byrne, B., \& Samuelsson, S. (2013). Longitudinal stability and predictors of poor oral comprehenders and poor decoders. Journal of Experimental Child Psychology, 115, 497-516.

II Elwér, Å., Gustafson, S., Byrne, B. Olson, R. K., Keenan, J., \& Samuelsson, S. (Submitted). A retrospective longitudinal study of cognitive and language skills in poor reading comprehension.

III Elwér, Å., Furnes, B., Gustafson S., \& Samuelsson, S. (Submitted) Pattern of preschool prediction of reading comprehension impairment: A 10 year longitudinal study. 


\section{Introduction}

Reading is essential in today's society, and teaching children to become proficient readers is one of the main goals of primary education. Reading consists of many different processes at different levels that need to be coordinated, including abilities, strategies and knowledge. Many children do not become avid readers and they struggle with reading throughout school.

An important aim of research in reading has been to determine how children at risk for reading difficulties may be identified as early as possible. If the children are discovered early, chances are that with appropriate intervention strategies educators can reduce or even prevent future difficulties. For this positive trend to occur, descriptions of the cognitive and language profile of readers with different types of difficulties across time are required.

For a long time reading difficulties have been associated with compromised decoding, that is dyslexic reading problems. However in the last 30 years, research has shown that many children with adequate decoding skills have difficulties understanding what they read. These readers are often called poor comprehenders (for reviews see Cain \& Oakhill, 2007; Hulme \& Snowling, 2011; Nation, 2005). Poor comprehenders have mostly been described as they are identified at age 8-9 or older, therefore relatively little is known about their cognitive and language profile over time, and especially early on in the development before they are exposed to reading instruction in grade 1 . The purpose of this thesis has been to describe the cognitive and language profile of children with reading comprehension difficulties using a longitudinal perspective. The thesis has especially focused on reading comprehension difficulties in children with adequate decoding skills, from preschool and through the first years of school.

The thesis starts with a presentation of the Simple View of Reading (Gough \& Tunmer, 1986) in the section "What is reading?". The two following sections describe the two components of the Simple View of Reading, decoding and comprehension. The fourth section describes skills that have been shown to be predictive of later reading performance. Reading difficulties are covered in the following section, starting with decoding difficulties followed by reading comprehension 
difficulties. Following sections describing methods, general aim of the thesis and summaries of the included papers is a general discussion of the results from all three studies.

\section{What is reading?}

In the 1970s there was a lively debate concerning the focus of reading instruction, phonics or whole language. The simple view of reading (Gough, Hoover, \& Peterson, 1996; Gough \& Tunmer, 1986; Hoover $\&$ Gough, 1990) could be seen as a first attempt to describe what later became "balanced literacy" (Kirby \& Savage, 2008; Pressley, 2006). The model explains reading comprehension as a product of decoding and linguistic comprehension, $\mathrm{R}=\mathrm{D} \times \mathrm{L}$. Each component can vary between 0 (inability) and 1 (perfection). Thus, both components are necessary to explain variance in reading performance. The decoding component is often operationalized as word reading accuracy. However, the simple view states that it should measure efficiency, and therefore, a speeded measure may be more appropriate (Hoover \& Gough, 1990). As for the linguistic comprehension component, it is often operationalized using listening comprehension tasks.

Several studies have shown that decoding and linguistic comprehension account for more than $70 \%$ of the variance in reading comprehension (Catts, Hogan, \& Adlof, 2005; Hoover \& Gough, 1990; Stanovich, Cunningham, \& Freeman, 1984). In addition Gough and colleagues (1996) have suggested that the relative importance of the two components change as word decoding gradually becomes automatized in most readers. For example, Catts and colleagues (2005) examined unique and shared variance of listening comprehension and word decoding on reading comprehension. They found that word recognition accounted for considerable unique variance in grade 2, whereas most of the variance in reading comprehension in grade 8 was explained by listening comprehension. Thus, as children get older, reading comprehension becomes more constrained by oral language comprehension rather than basic word-level decoding skill (Stanovich et al., 1984).

The Simple View of Reading does not suggest that the process of reading is simple, rather it states that the complexities associated with reading can be divided into two parts that are relatively independent 
(Hoover \& Gough, 1990). Linguistic comprehension can be seen as a construct which comprises a number of different language- related skills such as listening comprehension, vocabulary, grammar and morphology. It is not clear whether these skills can each individually serve as proxies for the linguistic comprehension component to the same degree (Farnia \& Geva, 2013). In fact, a number of studies suggest that other oral language skills such as vocabulary and grammar explain variance beyond the influence of listening comprehension on reading comprehension (Farnia \& Geva, 2013; Kendeou, van den Broek, White, \& Lynch, 2009). In this thesis, linguistic comprehension is seen as an umbrella term for a number of oral language processes such as listening comprehension, grammar, morphology, vocabulary and verbal memory.

The two subcomponents of the Simple View of Reading will be presented in the following two sections. First, there is a description of word reading which contains a report of what word reading is and how the development of word reading can be described in different phases.

\section{Word reading}

According to Ehri, there are four different ways to read words; decoding, reading by analogy, reading by prediction made from context and sight word reading (Ehri, 1991; see Coltheart, Rastle, Perry, Langdon, \& Ziegler, 2001 for a different example of conceptualization of word reading approaches). Decoding is also called phonological recoding; with this procedure graphemes are translated to phonemes that are blended together, either one by one, or as larger chunk units which make up the words (Ehri, 2005).

Words can also be read with analogy to other words (Goswami, 1986). This strategy can be used when a word is very similar to a familiar word, for example bike and hike. Another strategy of reading is to make predictions based on the context of the text. Basically, the reader guesses what the next word will be with reference to the content in the text and letter cues. (Goodman, 1970; Tunmer \& Chapman, 1998).

Decoding, reading by analogy and prediction from context can be used when reading unfamiliar words. However, with sight word reading, only familiar words can be read. This happens spontaneously 
without any conscious effort. Sight word reading, also called orthographic reading, is the most precise and efficient way to read. Essentially, words are read automatically from memory. Learning to read words by sight is a matter of forming connections between graphemes and phonemes. With practise and repeated exposure of common spelling patterns within words, the grapheme-phoneme correspondences becomes consolidated into larger units that are easily activated when they are read (Ehri, 2005). Strong connections between the words or part of words and the phonological representation of the word are created; therefore they are consolidated and easily remembered. In sight word reading, words are read without pausing between different units within words (unitization) (Ehri, 2005). While the less sophisticated methods of reading explained above may temporarily disrupt the focus of the text to the word unit, when using sight word reading all resources can be allocated to reading comprehension. But how do children go from preliterate to being able to decode words efficiently through sight word reading? The next section describes an influential way to look at phases of decoding development.

\section{Phases of decoding development}

Ehri has described the process of becoming a skilled decoder using four different developmental phases (Ehri, 1991; 2005). Ehri's phases describe the type of alphabetic knowledge that is predominant at different time points in the development. The phases are not distinct; rather children can apply alphabetic knowledge of different kinds as they gradually learn to read fluently. The phases are called prealphabetic, partial alphabetic, full alphabetic and consolidated alphabetic. In the pre-alphabetic phase, children know very little about the alphabetic system and do not apply the principle of graphemephoneme correspondences when they read. If they do read at all, they use evident visual features of some words as cues. Their ability to recognize words are often tied to fonts, or colors as in brand names of products (environmental print: Masonheimer, Drum, Ehri, 1984) or on letters of their own first name (Bloodgood, 1999).

When the children learn the names or sounds of some letters they progress to the partial alphabetic phase (Ehri, 2005). In this phase, children begin to have some knowledge of letter-sound 
correspondences and they take advantage of this knowledge as they read. As an example children in this phase may read $J R F$ as giraffe. The knowledge of the alphabetic system is still incomplete and the children are unable to segment the words into all of its corresponding phonemes and can subsequently not read unfamiliar words. Ehri and Wilce (1985) termed this reading "phonetic cue reading" as the names of the letters are often used as cues. It is important to distinguish between the phonetic cue reading where the reader does not have a full account of the alphabetic system, and sight word reading that emerges later. If children acquire knowledge of the alphabetic system quickly, they may exhibit the behavior associated with the partial alphabetic phase for a very brief period of time.

Decoding development is initiated by phonological awareness (PA) in combination with letter knowledge (Stuart \& Coltheart, 1988). When children have complete knowledge of the alphabetic system and how the letters correspond to the sounds, they exhibit full alphabetic phase behavior. According to Ehri and Wilce (1979), the graphemephoneme correspondences are the mnemonic system that ties pronunciations with their spellings in memory, and thus enhances memory for words. In this phase, children can read new words that they have never encountered before. Initially, even very short and simple words are sounded out letter by letter, but eventually common words are read effortlessly (Ehri, 2005). Decoding works as a selfteaching strategy for sight words, such that new words are read and coded into memory (Share, 1995).

In the consolidated alphabetic phase, the alphabetic units that are primarily used are chunks of letters. These chunks consist of morphemes, onsets and rhymes, short monosyllabic words and frequent spellings of words (Ehri, 2005). Reading words in different chunks instead of decoding words letter by letter decrease the burden on the memory system. The consolidated alphabetic phase is characterized by fast and efficient reading of words by sight. 


\section{Comprehension}

Comprehension of language entails understanding of individual words but also active engagement with the content to create a mental representation. Successful comprehension requires coordination of skills at many levels to extract and construct meaning. The section on comprehension consists of four parts. In the first part, a simple example is used to introduce a few commonly used concepts associated with comprehension. In the second part, some important distinctions in comprehension in different formats are suggested. In the third part, a brief description of a comprehension model, the CI-model (Kintsch \& Rawson, 2005; Kintsch \& van Dijk, 1978) is presented. The CI-model describes how comprehension can be obtained using different levels of processing. The purpose of these sections is to suggest complexities associated with reading comprehension which are important when considering children with reading comprehension difficulties. The last section is called "Assessment of reading comprehension". Given the complexity of reading comprehension it is not surprising that the skill is not easily assessed. Differences between tests potentially influence selection of groups with compromised results (Keenan \& Meenan, 2014).

\section{A comprehension example}

An example of a simple text is presented below. This text will be used to demonstrate some important concepts of comprehension.

An hour before the guests arrived, Henry went downstairs to get started on the frosting for the cake. He was mystified. The cake was nowhere to be seen. Looking down, he saw crumbs on the floor and Molly, his German Shepard, was lying in her basket licking her mouth. Henry bit his tongue and started taking out the ingredients.

To understand a text the individual words have to be decoded and the meaning of the individual words accessed. Some words may be unknown to the reader which will disturb reading flow. Also, words which are not pronounced in accordance with pronunciation rules may 
introduce challenges in mapping to the correct word. Often, understanding of a sentence or a clause does not entail merely adding up the meanings of the individual words. An example in the text above is the idiomatic expression "to bite his tongue" which is to be interpreted not by the literal meaning but rather the figurative meaning, (to struggle not to say something you really want to say). This is true for a number of different text elements in literate language including metaphors and analogies (Westby, 2012).

To understand texts you also have to make inferences. Making inferences refers to filling in information which is not stated explicitly in the text. In the text above you need to make the inference that Molly ate the cake and that Henry intended to bake a new cake for the guests. These inferences require readers to integrate information across sentences. Without the inferred meanings the text does not make much sense. Several different classification systems have been suggested for inferences (Graesser, Singer, \& Trabasso, 1994). A common type of inferences in expository texts is causal inferences, which are necessary to identify actions which are consequences of other actions (Westby, 2012).

The importance of knowledge in comprehension cannot be emphasized enough (Elbro \& Buch-Iversen, 2013; Tarchi, 2010). For example, knowledge of the world is necessary to make text connections such as inferences. A common way to conceptualize the knowledge necessary in reading is by using the concept schema. According to Mandler, (1984) schema is a hierarchical organization of knowledge about an event or object. Thus, schema is a way to conceptualize the existent knowledge structures that we use to understand. The hierarchical organization helps us to prioritize what to focus on in complex situations. The schema enable us to behave appropriately in situations previously experienced and also to be able to make the connections that are necessary to comprehend written or spoken discourse. In the example above, knowledge about how dogs behave and the fact that many dogs eat all types of food can help you make the inference that the dog ate the cake.

\section{Different types of comprehension}

The processes involved in comprehension in oral and written language share many features. For example, inferences are made in 
comprehension of oral language as well as when reading. However, it is still beneficial to make two distinctions concerning usage of language; academic vs everyday language, and written vs spoken language.

The level of difficulty associated with comprehension of certain content depends on the complexity of the language used. There are important differences between the language that we use in every day conversations and the language used in school (Westby, 2012). Everyday conversations are primarily used to achieve daily tasks and share personal information. Academic language, on the other hand, includes a different set of words, more complex grammatical structures and different text organization to express content which describe complex relationships (Zwiers, 2008). Also, academic language is much more lexicalized; each clause has a higher density of words which carry the meaning of the text compared to everyday language (Westby, 2012). Other language constructs associated with academic texts are nominalizations, that is verbs or adjectives are used to form nouns. An example of a nominalization is conclusion which stems from the verb conclude. Passive voice is also commonly used in academic language.

Although, written and spoken language come in many different forms there are some general differences between language in the two modalities. Whereas speech is temporary, written language is permanent. This means that the reader has opportunities to recover from comprehension failure by going back to the text. However, written language stands without many of the contextual cues that help convey the message in oral language (Cain, 2010). Gestures and intonation patterns are quite helpful in getting the message across in spoken language. But most important is the social context of the message in the spoken form. Spoken language is interactive and used in a conversational context, therefore the content is often negotiated and the shared situation provides additional help in interpreting the spoken message. In this sense texts are decontextualized.

Time is a factor when considering differences between written and spoken language. Chafe and Danielewicz (1987) showed that the vocabulary used in spoken language was less varied compared to text. This was not only the case in every day conversations but also in academic lectures. Normally writers spend a lot of time searching for the exact word that will best deliver the content. However, in spoken 
language, words are chosen on the fly; therefore the content is often less elaborated, and not formulated with the same precision. Some words that are common in writing are rarely used in spoken language, for example thus and accordingly. Whereas written language is quite traditional, it has been suggested that oral language favors new vocabulary (Chafe \& Danielewicz, 1987).

Some general differences should also be mentioned with regard to syntax of discourse in the two different modalities. Speakers are more likely to use simple chain clauses, whereas writers used more elaborate clause structures (Cain, 2010). This difference inevitably makes written language more complicated to understand. Also spoken language is full of repetition and rephrasing, and a relatively high number of words are often used to present a small amount of information compared to written texts (Kahmi \& Catts, 2012).

To sum up, written language, especially in an academic context, is associated with a number of complexities. The language used in texts use more rare vocabulary and sentence structures which are complex compared to spoken language. Also, texts stand without the context given by a shared situation in oral conversations. Given these differences it is not surprising that some children exhibit difficulties in reading comprehension.

\section{A comprehension model}

A number of different models have been proposed to account for the complex process of understanding text (mental models: Gernsbacher, 1990; Johnson-Laird 1983; Construction Intergration Model: Kintsch \& Rawson 2005, Kintsch \& van Dijk, 1978). These models include bottom-up models, top-down models and parallel models. In bottomup models, the process of reading for understanding starts with the written words and comprehension is constructed by building the representation stepwise from the individual phoneme to understanding of the entire text. Top-down models emphasize the importance of inference making and schemas used to predict the content of the texts. In parallel models, it is suggested that these two processes work in parallel, simultaneously (Kahmi \& Catts, 2012).

The Construction Integration (CI) Model by Kintsch and colleagues (Kintsch \& Rawson, 2005; Kintsch \& van Dijk, 1978) has been highly influential in the field. Early versions of the CI-model 
described reading comprehension in terms of a parallel processing model, but in later versions the CI-model would qualify as bottom-up (Kintsch, 1998).

The ultimate goal of reading is to obtain a coherent mental representation of the meaning of the text. By testing what people remember of a text, we can try to understand what this representation consists of. In general, individuals do not exhibit good verbatim recollection of a text. Thus, the process of understanding does not entail memorizing of words but rather integrating and constructing a model (Kintsch \& Rawson, 2005). In the model, integration of information from different sentences and segments of text are linked and combined with the reader's knowledge. The CI-model proposes two separate processes within a connectionist framework; constructing and integrating (Kintsch \& Rawson, 2005, Kintsch \& van Dijk, 1978).

During the construction phase a word is read and the meaning of that word is activated. For words with multiple meanings, all semantic representations are activated along with words associated with the target word. Understanding is built based on simple statements (propositions) that form a network of associations called microstructure. To establish this microstructure, the reader has to make connections between the different propositions. Making a causal-based inference is one example of such a connection. At this stage a literal version of the text, text-base, is constructed based on decoding, vocabulary and background knowledge. In the construction phase, all word meanings are activated, even incorrect ones, therefore the representation in text-base is not yet coherent.

In the integration phase, activations are spread in the network, through inference processing. This results in a stable activation pattern, such that meanings can be inferred. The integration process is a slow and sometimes effortful process. At the next level text segments are related to each other and at this level the macrostructure of the text is built. Building of macro structure includes identification of key themes and their relationship to each other. This can be done by using signaling devises such as headings, repetition of words and first line information.

To establish a situation model, background knowledge is used to form connections between nodes from long-term memory, to make inferences and to interpret the content of the text. The situation model is not restricted to the verbal domain; it can also include imagery, 
emotions and personal experiences. The rich representation of the content that the situation model comprises is stable and robust and more persistent in memory compared to content that only includes text base knowledge.

\section{Assessment of reading comprehension}

Tests assessing reading comprehension have often been used interchangeably, suggesting an implicit assumption that they all measure the same thing (Keenan, Betjemann, \& Olson, 2008). As reading comprehension relies on both word decoding and linguistic comprehension, a valid assessment of reading comprehension should tap both skills. A few studies have examined the amount of variance in reading comprehension which can be explained by different components underlying reading comprehension. These studies have suggested large variations between tests (Cutting \& Scarborough, 2006; Francis, Fletcher, Catts, \& Tomblin, 2005; Keenan et al., 2008; Nation \& Snowling, 1997).

Different response formats have been used in tests to assess reading comprehension. Common formats include cloze tests, multiple choice tests and tests with open ended questions (Cain, 2010). In a cloze test, each item contains a sentence or paragraph with a word missing. The reader is instructed to find a word that fits the context. Two studies have suggested that cloze tasks show a stronger relationship with decoding compared to other formats (Francis et al., 2005; Nation \& Snowling, 1997). In the study by Nation and Snowling (1997), the results for the cloze test suggested that listening comprehension did not account for any additional variance in reading comprehension once decoding was included in the statistical model. In a more recent study by Keenan et al. (2008), it was suggested that passage length rather than response format determined how closely related the tests were to decoding skill. That is, short passages are more dependent on decoding skills compared to longer passages. The authors argue that when children read passages with few sentences, successful reading comprehension is dependent on correct decoding of each individual word. In longer passages, the events are given a richer description, which makes it easier for children to use the context for comprehension. Thus, it may be easier to recover from unsuccessful 
decoding in longer passages. This pattern was especially apparent in younger children.

Another type of reading comprehension tests applies open ended questions. The Neale Analysis of Reading Ability (NARA: Neale, 1997) applies a procedure with long passages and open-ended questions. Performance with this type of task has been suggested to be more dependent on listening comprehension and inference making compared to other formats (Cain \& Oakhill, 1999; Nation \& Snowling, 1997), but also to be influenced by metacognitive aspects, expressive speech and self-confidence (Spooner, Baddeley, \& Gathercole, 2004).

Multiple choice tests have been used to assess comprehension of figurative language such as idiomatic expressions (Cain, 2010). With a multiple choice procedure, literal as well as figurative meanings can be used as response alternatives. However, a disadvantage of this procedure is that the inferences have to be spelled out. If the correct choice is most closely associated with the text itself, the correct choice can be made even though the reader did not make the target inference.

Another potential problem, associated with reading comprehension assessment is whether the questions could be answered using general knowledge instead of knowledge achieved from reading the text (Keenan \& Betjemann, 2006). Keenan and Betjemann (2006) found that in a commonly used reading comprehension test, many of the questions were passage independent; if you had the appropriate background knowledge, you did not have to read the text.

To sum up, reading comprehension tests cannot be used interchangeably. Rather, there are advantages and disadvantages with different formats, and the results of the tests show differential patterns of explained variance in terms of underlying constructs. The pattern can also vary across age. 


\section{Early predictors of reading}

During the last 30 years many studies have shown longitudinal relationships between cognitive and language skills and later reading skills in the normal range as well as in populations with reading difficulties. These studies have shown that when children have been exposed to reading instruction, the prediction of future levels of decoding skills can be done with relatively high accuracy. The reason for this is that children who make a good start in reading development often continue to show a positive trend. On the other hand, children who struggle early on often do so continually (Scarborough, 1998). Prediction of reading skills starting in preschool or kindergarten, when very few children have any reading ability, is much more difficult.

In an influential meta-analysis, Scarborough (1998) examined early prediction studies that were conducted between 1976 and 1996. More than 60 prediction studies examining prediction of individual differences in decoding were included in the analysis. The results showed that more than 20 different skills predicted future decoding performance, and that the three most important predictors were letter identification, PA and rapid automatized naming (RAN).

Other variables often used to predict reading performance such as vocabulary, verbal memory and grammar, are more closely related to reading comprehension than to decoding (Roth, Speece, \& Cooper, 2002). However, when reading performance in the first years of school is examined, the division between predictors of decoding and reading comprehension is not straight forward. For instance, some studies have suggested that early levels of PA and print knowledge predict later reading comprehension (Aarnoutse, van Leeuwe, \& Verhoeven, 2005; Adlof, Catts, \& Lee, 2010) even when controlling for word reading performance (Parrila, Kirby, \& McQuarrie, 2004). Also, vocabulary and knowledge of grammatical structures have been found to predict later decoding skills (Muter, Hulme, Snowling, \& Stevenson, 2004).

Six different skills have been used to predict reading in this thesis and they are commonly used within the field; these are PA, RAN, print knowledge, vocabulary, grammatical skills and verbal memory. The sections presented below will explain the six different constructs and the types of tasks that are often used to assess them. Also, previous 
prediction studies of decoding and reading comprehension will be presented. As the focus of this thesis is on preschool predictors, the studies reviewed will mainly involve studies from preschool and kindergarten age. The relationship between these predictors and subtypes of poor readers such as poor decoders and poor comprehenders will be described in the section "Reading difficulties".

\section{Print knowledge}

Even before children are exposed to formal reading instruction, many have some knowledge associated with print. For example, they may have some knowledge of letters, recognize what distinguishes text from other symbols and know that text is read from left to right. Children may also have logographic representations of some words, for example their own name, or a brand of a favorite product. The concept of print knowledge entails all these aspects. The most commonly assessed aspect of print knowledge is letter names and letter sounds. Scarborough (1998) found that letter knowledge showed a correlation of $r=.52$ with subsequent reading performance (see also Lonigan, Burgess, \& Anthony, 2000; Muter et al., 2004; Shapiro, Carroll, \& Solity, 2013; Storch \& Whitehurst, 2002 for similar findings).

Several explanations have been put forward to account for the close relationship between letter knowledge and early reading skill (Adams, 1990). For instance, a child who has mastered the letter names may with more ease learn about letter sounds and how to map them to graphemes, as the letter symbols themselves are manifest knowledge. Also the letter names are closely related to their sounds, and therefore letter names could be used as cues for letter sounds in children as they begin to read. Thus, knowing the letters is an important first step in learning to read, but to understand the alphabetic principle, children have to be able to recognize and manipulate letter sounds. These aspects are assessed with tasks measuring PA.

\section{Phonological awareness (PA)}

Three different skills that make use of the sound structure of language have been associated with word reading; PA, RAN and verbal working memory (Wagner \& Torgesen, 1987). These three skills have been 
termed phonological processing skills. The most widely recognized skill associated with early reading is PA.

Massive evidence support PA as an important predictor of early reading performance (Frost, Madsbjerg, Niedersøe, Olofsson, \& Sørensen, 2005; Furnes \& Samuelsson, 2010; Melby-Lervåg, Lyster, \& Hulme, 2012; Parrila et al., 2004; Scarborough, 1998; Torgesen, Wagner, Rashotte, Burgess, \& Hecht, 1997; Wagner, Torgesen, \& Rashotte, 1994). Scarborough (1998) have reported mean correlations of $r=.45$ between preschool/kindergarten performance of PA and early decoding skills. PA can be defined as "the conceptual understanding and explicit awareness that spoken words consist of individual speech sounds (phonemes) and combinations of speech sounds (syllables, onset-rime units)" (Vellutino, Fletcher, Snowling, \& Scanlon, 2004, pp. 4-5).

Tests of PA are assumed to capture underlying phonological representations of lexical items in the mental lexicon (Elbro, Borstrøm, \& Petersen, 1998). It has been suggested that distinct phonological representations help in the development of PA and the development of reading and spelling skills (Snowling, 2000). PA is assessed at different complexity levels. A simple task of PA involves recognition of units bigger than the phoneme, such as parts of words or syllables. A more difficult task involves manipulation of phonemes (for example blending or substitution). The related term phonemic awareness refers to identification and manipulation at the phoneme level, whereas PA can entail larger chunks of sounds as well.

Why is phonemic awareness important in learning to read? Three reasons have been proposed by Al Otaiba, Kosanovich and Torgesen (2012). First, it helps children understand the alphabetic principle and develop alphabetic knowledge. Second, it helps children notice the regular ways that letters represent sounds of words. Third, it helps children to become flexible readers, such that they can decode even irregular words. For instance, if a word is difficult to decode as it is irregular, children can search their lexicon for words beginning with a certain sound which has been successfully decoded.

However, another line of research suggests that PA can be seen as a secondary consequence of reading instruction itself and thus is not causally related to reading (Goswami \& Bryant, 1990). It has also been suggested that the relationship between PA and early decoding is reciprocal (Perfetti, Beck, Bell, \& Hughes, 1987). Evidence for this 
line of arguing can be found in studies showing that phonemic awareness tasks are too difficult for many pre-readers (de Jong \& van der Leij, 1999; Liberman, Shankweiler, Fischer, \& Carter, 1974). Also, Ehri (1989) has pointed out that the majority of 5 year olds who show phonemic weaknesses at age 5 do not end up as poor readers later in development.

A third predictor that has been attributed great importance in early reading prediction is the speed at which children can name well known symbols or objects; RAN.

\section{Rapid Automatized Naming (RAN)}

In 1974, two medical doctors, Denkla and Rudel, made the observation that many children selected for poor decoding skills were slower than average in naming well known objects with speed (Denkla \& Rudel, 1974a; 1974b). They developed the Rapid Automatized Naming (RAN) tasks, which has since been expanded and used in different versions and using different stimuli. In essence, familiar objects, colors or symbols such as letters and numbers are presented in a grid-like format. Sometimes the stimuli are repeated several times within the grid. Subjects are asked to name the stimuli as fast and accurately as they can. Since the discovery by Denkla and Rudel (1974a; 1974b) a number of studies have found that RAN is a good predictor of individual differences in reading (e.g. Lervåg \& Hulme, 2009; Norton \& Wolf, 2012; Powell, Stainthorp, Stuart, Garwood, \& Quinlan, 2007; Scarborough, 1998; Wagner \& Torgesen, 1987). The strongest relationship has been found between RAN and reading fluency tasks (Schatschneider, Fletcher, Francis, Carlson, \& Foorman, 2004).

Despite a wealth of studies that have tried to identify common processes underlying reading and RAN, the relationship has not been properly explained. RAN and reading share many features that may account for the relationship between the two skills. For example, both skills involve the speed of retrieving phonological representations from memory (Wagner \& Torgesen, 1987). Another explanation of the relationship between reading and RAN has been put forward by Kail and colleagues (Kail, Hall, \& Caskey, 1999). They suggest that a third underlying mechanism could influence both these skills, the most likely candidate being general processing speed. This mechanism would also account for slow processing in other domains. 
As have been explained above, print knowledge, PA and RAN are commonly reported predictors of later decoding. The next three predictors, vocabulary, grammar and verbal memory have been suggested to have a closer relationship with reading comprehension.

\section{Vocabulary}

Although many agree that vocabulary is important for successful reading, there is no consensus about the nature of the relationship between oral language and reading. Often, studies control for vocabulary knowledge and verbal IQ and thus ignore the contribution from an important area of language (Nation, 2005).

Measurements of vocabulary are often divided into expressive or receptive. Receptive vocabulary refers to the words that are understood by an individual when he/she hears or reads them. Expressive vocabulary is the words that are used when he/she speaks. Another distinction is breadth and depth. Vocabulary breadth is the number of entities in the mental lexicon and vocabulary depth refers to the extent of semantic representation for the words in the lexicon (Ouellette, 2006). In this perspective vocabulary growth consists of both adding more entities to the mental lexicon and refining word meaning over time. Breadth and depth of vocabulary have also been shown to have partly different prediction patterns in reading. For example, Ouellette (2006) found that vocabulary breadth was a significant predictor of decoding, whereas vocabulary depth was more closely associated with reading comprehension for children in grade 4 .

Numerous studies have suggested that vocabulary has a close relationship with reading comprehension (e.g., Anderson \& Freebody, 1981; Beck, Perfetti, \& McKeown, 1982; McKeown, Beck, Omanson, \& Perfetti, 1983; Olson et al., 2011). Preschool vocabulary has been shown to be an important predictor of later reading comprehension (Muter et al., 2004). Vocabulary also continues to influence reading comprehension when word reading skills are automatized in most readers (Ouellette, 2006; Ricketts, Nation, \& Bishop, 2007; Sénéchal, Ouellette, \& Rodney, 2006). In addition, vocabulary interventions have shown significant effects on reading comprehension in population samples (Elleman, Lindo, Morphy, \& Compton, 2009; Stahl \& Fairbanks, 1986). 
Two different positions can be identified with regard to the predictive relationship between vocabulary and reading comprehension. It has been suggested that vocabulary (or oral language skills) influence reading comprehension only after decoding skills have been established (Speece, Roth, Cooper, \& de la Paz, 1999; Vellutino, Tunmer, Jaccard, \& Chen, 2007). However, some studies suggest that oral language skills are essential in early reading comprehension (Bishop \& Adams, 1990; Catts, Fey, Zhang, \& Tomblin, 2001). Kendeou et al. (2009) compared the influence of early decoding-related skills and oral language skills on reading comprehension in grade 2 . They found that both types of skills made important unique contributions to reading comprehension. They also found that the decoding-related skills and oral language skills were closely related to each other in preschool but became more independent after a few years of school.

\section{Verbal memory}

Verbal memory is conceptualized as the ability to store verbal information in temporary storage. A division can be made between working memory tasks, which involve simultaneous storage and processing, and short term memory tasks, which comprise passive storage and retrieval (Baddeley \& Hitch, 1974; Kolb \& Wishaw, 2009). Assessment can involve many different types of tasks commonly using words or sentences.

As have been described previously, verbal working memory has been operationalized as one of three phonological processing skills (Wagner \& Torgesen, 1987). As such, verbal memory would be expected to show strong relationships with decoding development. However the results are mixed. Some studies suggest a strong relationship between early verbal working memory and later reading development (Swanson \& Alexander, 1997; Swanson \& Siegel, 2001). Other studies indicate that verbal memory may play a minor role in prediction of reading when considered together with PA and/or RAN (Bowers, 1995; de Jong \& van der Leij, 1999; Parrila et al., 2004; Wagner et al., 1997). Separating memory skills from language skills is not an easy task, thus it is complicated to achieve valid measurements on the influence of memory on reading. 
Based on her meta-analysis, Scarborough (1998) suggested that verbal memory tasks that involve both memory and sentence processing abilities, such as repetition of sentences or recall of a brief orally presented story, were more strongly related to children's future reading achievement compared to tasks such as digit span, word span and pseudo-word repetition measures. The results of Scarborough's meta-analysis showed correlations between $r=.45$ and $r=.49$ for sentence processing in combination with memory and reading and $r=$ .31 to $r=.33$ ) for task involving passive storage.

The relationship between verbal memory and reading comprehension has been established in college populations (Daneman \& Carpenter, 1980) and in children (de Beni, Palladino, Pazzaglia, \& Cornoldi, 1998; Seigneruic, Ehrlisch, Oakhill, \& Yuill, 2000). It has been suggested that poor working memory capacity influences performance on all levels of comprehension and could therefore potentially be causally related to reading comprehension (Perfetti, Marron, \& Foltz, 1996).

\section{Grammar}

Grammar constitutes a set of rules governing the composition of clauses, phrases and words in a language. Although grammatical knowledge has been shown to be related to different aspects of reading, the nature of the relationship has not been easy to describe. Two different aspects of grammar are morphology and syntax. Morphology refers to the internal structure of words and how words relate to each other (Akmajian, Demers, Farmer \& Harnish, 1997). Simply put morphology deals with morphemes, the smallest grammatical unit of the language. Syntax refers to the internal structure of sentences and relationships between words within a sentence (Akmajian et al., 1997).

Tasks that are often used to assess syntax include word order correction tasks or grammatical correction tasks (Cain, 2007). In these types of tasks, individuals are given clauses that contain grammatical errors and are asked to provide the correct clause. To access morphology, morphological generation tasks are commonly used. When given a picture and a stem sentence, the child is required to produce a variation of the target word using a different morphological 
ending. For example, "Here is a tree, here are two .....". This type of task can also be done using non-words.

Grammatical knowledge has been found to influence both word reading and reading comprehension, however it is likely that the association is stronger with reading comprehension (Storch \& Whitehurst, 2002; Vellutino et al., 2004)). It has been suggested that syntax influences word reading if readers can use the constraints provided by syntax to decode an unknown word (Rego \& Bryant, 1993). In a sense, the syntax of the sentence provides a grammatical context that supports decoding.

Studies have found important influence from early grammatical skills to later reading comprehension. In a longitudinal study, Muter and colleagues (Muter et al., 2004) examined children for two years starting when the children were approaching their 5th birthday. Reading comprehension was explained by previous word reading ability, vocabulary and grammatical skills. For reading comprehension in the later grades, grammatical knowledge may influence by facilitating text level integration and monitoring of reading (Bowey, 1986). Bowey (1986) found that syntactic awareness tasks were correlated with reading comprehension and monitoring skills in less skilled readers in grades 4 and 5. These relationships remained significant when controlling for vocabulary.

However, the predictive power of grammatical knowledge and in particular syntactic awareness has been questioned. Cain (2007) examined prediction of reading in 8-10 year olds. She found that syntactic awareness explained unique variance in word reading but not in reading comprehension. Based on her results, she suggested that the relationship between reading comprehension and syntactic awareness might exist because of shared underlying constructs of memory and vocabulary that influences both skills.

\section{Causal predictors}

The paragraphs above have briefly described six different skills which have been found to be related to reading development in different ways. The studies that have been summarized are mostly correlational studies; therefore causal claims cannot be made based on these studies. However, in addition to all the correlational studies showing that PA is one of the strongest predictors of future reading, 
training studies have given support to a causal claim for PA. Training of PA has been shown to affect word reading development (Bus \& van IJzendorn, 1999; Byrne \& Fielding Barnsley, 1993; Ehri, Nunes, Stahl, \& Willows, 2001; Lundberg, Frost, \& Peterson, 1998). These results, along with the fact that deficits in PA are included in a typical cognitive profile of children with dyslexia (Cardoso-Martins \& Pennington, 2004; Lyytinen et al., 2006), have led to a strong claim that PA is causally related to decoding development (however see Castles \& Coltheart, 2004 for a discussion of weaknesses in this line of argumentation). Concerning the oral language skills, vocabulary stands out as the most likely candidate for causal relationships given strong associations with reading comprehension (Olson et al., 2011; Ouellette, 2006) and successful intervention results (Clarke, Snowling, Truelove, \& Hulme, 2010).

Many of the predictors that influence individual differences in reading have are also been found to be compromised in children with different types of reading difficulties. Now we turn to a description of two types of reading difficulties which are of relevance to this thesis; decoding difficulties and reading comprehension difficulties in children with adequate decoding.

\section{Reading Difficulties}

Reading comprehension deficits can be found in many different types of populations, both developmentally and in adults. Based on the Simple View of Reading, a deficit in reading comprehension is the result of a specific problem in one of the two skills involved in reading comprehension (i.e., decoding or linguistic comprehension) or a combination of deficits in both skills (Aaron, Joshi, \& Williams, 1999; Catts, Adlof, \& Weismer, 2006; Catts, Hogan, \& Fey, 2003). In this thesis, two subtypes of poor readers will be examined, children with poor decoding on the one hand and poor comprehension on the other. Different sorts of selection procedures will be used to identify these subtypes of reading difficulties. 


\section{Decoding difficulties}

Reading and writing difficulties have been the focus of many studies since the beginning of the 1960s (Vellutino et al., 2004). These studies have mainly focused on children with poor decoding skills, often defined as dyslexic reading problems, and the literature on its causes and consequences as well as remediation is extensive (Ehri et al., 2001; Snowling, 2000; Stanovich, 1986; Stanovich \& Siegel, 1994; Vellutino et al., 2004). Individuals with dyslexia have unexpectedly poor decoding skills based on their general ability despite adequate teaching. Dyslexia can be defined as in the following:

Dyslexia is a specific learning disability that is neurobiological in origin. It is characterized by difficulties with accurate and/or fluent word recognition and by poor spelling and decoding abilities. These difficulties typically results from a deficit in the phonological component of language that is often unexpected in relation to other cognitive abilities and the provision of effective classroom instruction. Secondary consequences may include problems in reading comprehension and reduced reading experience that can impede growth of vocabulary and background knowledge. (Lyon, Shaywitz and Shaywitz, 2003, p. 2).

Individuals with dyslexia have problems establishing the grapheme-phoneme correspondences that are the basis of decoding, and hence they struggle immensely with their reading. The most typical manifestation of dyslexia is failure to reach automatic decoding (Snowling, 2000). Although children with dyslexia with time often learn to decode words correctly, the process continues to be effortful and slow into adulthood (Bruck, 1990). The decoding deficit is sometimes most clearly apparent in reading of non-words (Snowling, Stackhouse, \& Rack, 1986). When reading non-words, contextual cues cannot be used to determine the word in question; instead the word has to be decoded. Relatedly, the ability to correctly spell familiar words is often compromised (Vellutino et al., 2004).

For a long time researchers have been trying to find the underlying causal mechanisms of developmental dyslexia. There is now converging evidence that weak phonological coding is the underlying cause of reading difficulties (Ehri et al., 2001; Stanovich, 1988; 
Stanovich \& Siegel, 1994; Vellutino et al., 2004). Individuals with dyslexia exhibit specific impairments in representation, storage and/or retrieval of speech sounds. If the sounds are poorly represented this affects learning grapheme-phoneme correspondences which are the basis of early reading acquisition. This has lead researchers to suggest that individuals with dyslexia may have poorly specified phonological representations (Elbro et al., 1998; Griffiths \& Snowling, 2002; Snowling, 2000). Individuals with dyslexic reading problems commonly exhibit poor PA, compromised verbal short term memory and slow RAN (Cardoso-Martins \& Pennington, 2004; Lyytinen et al., 2006). Despite the distinguishing pattern of RAN in different groups of readers, no clear causal link has been established between RAN and early reading skills (de Jong \& Vrielink, 2004).

Despite abundant support for the phonological deficit theory, causal paths of dyslexia continue to be debated. The alternative theories regard the phonological processing deficit found in children with dyslexia as merely a manifestation of much more widespread deficit stemming from impairments in general cognitive and motor functions. The three most widely recognized alternative theories are the auditory theory (Tallal, 1980; Tallal, Miller, \& Fitch, 1993), the visual theory (Livingstone, Rosen, Drislane, \& Galaburda, 1991; Lovegrove, Bowling, Badcock, \& Blackwood, 1980) and the cerebellar theory (Nicolson \& Fawcett, 1990; Nicolson, Fawcett, \& Dean, 2001). These theories propose that dyslexic reading problems are caused by auditory deficits, visual deficits and motor functions respectively. In a multiple case study of dyslexic college students, Ramus and colleagues (2003) examined the extent to which their subjects exhibited deficits in line with the four main theories of dyslexia. All individuals exhibited phonological deficits. Although quite a few (10 out of 16) exhibited auditory deficits, the type of auditory deficits varied between individuals. None of the participant exhibited difficulties with rapid auditory processing or had problems that were specific to speech, which is the core of the auditory theory (Tallal, 1980; Tallal et al., 1993). The auditory deficits did however have an impact on phonological processing, explaining 30\% of the variation. Only 4 of the individuals exhibited motor problems and 2 exhibited visual problems. Along with many other studies these results give support to the phonological deficit theory and suggest that other sensory and 
motor disorders may be present in certain individuals (e.g. Elbro et al., 1998; Stanovich, 1986).

Practitioners of different sorts, such as psychologists, speech and language pathologists or medical doctors, can be involved in diagnosing dyslexia. Often diagnosing involves a thorough examination of different cognitive and language skills. However, the common way in research today is selection of children whose performance is in the low tail on decoding tests. This approach has been used in the present study.

\section{The double deficit hypothesis}

As presented above there is a consensus that phonological deficits underlie reading difficulties in many children. RAN has been described as a phonological processing skill (Wagner \& Torgesen, 1987). However, there is considerable heterogeneity concerning deficits exhibited by groups of children with reading disabilities. The double deficit hypothesis proposes that ..."phonological deficits and the processes underlying RAN are separate sources of reading dysfunction, and their combined presence leads to profound reading impairment" (Wolf \& Bowers, 1999, p. 416). The theory suggest that there are three different profiles of difficulties associated with reading disability; selective phonological deficits, selective RAN deficits and combined deficits (Wolf \& Bowers, 1999). According to the theory the phonological subtype should show compromised PA, word attack and reading comprehension, whereas the RAN subtype would show compromised RAN, reading fluency and reading comprehension. The combined subtype is expected to show both types of deficits and are compromised on all tasks associated with reading. Wolf and Bowers (1999) emphasized that the double deficit theory should have extensive influence on identification and remediation.

Support for the double deficit hypothesis is extensive and has been found in cross sectional and longitudinal studies (Papadopoulos, Georgiou, \& Kendeou, 2009; Torppa, Georgiou, Salmi, Eklund, \& Lyytinen, 2012). However, some studies also fail to find important characteristics of the theory (e.g., Schatschneider \& Carlson, 2002). Comparisons between studies are complicated by statistical artifacts such as differences in tests used and cut points applied (Vukovic \& Siegel, 2006). 


\section{Decoding deficits and reading comprehension}

Decoding deficits often affect reading comprehension ability. A comprehensible explanation was outlined by Perfetti (1985) in the bottle-neck theory of automaticity. It states that within a limited capacity system, decoding skills have to be automatized such that capacity can be allocated to higher-order-level processes necessary for successful reading comprehension.

In 1986, Stanovich suggested that poor readers might spend less time reading and will therefore fall behind typical readers on vocabulary and general knowledge. He called this phenomenon "the Mathew effect of reading". Though this may be true for some, it is not true for all readers (Scarborough \& Parker, 2003). It has also been suggested that individuals with decoding deficits often use compensatory strategies, such as reliance on context, to achieve successful comprehension of written text (Kirby, Silvestri, Allingham, Parrila, \& La Fave, 2008).

\section{Reading comprehension difficulties}

Reading comprehension and decoding are typically highly correlated in the early grades (Florit \& Cain, 2011; Gough et al., 1996). However, some individuals are exceptions to this general pattern of highly correlated results for these skills. The last 25 years of research in reading comprehension has shown that a relatively large group of readers show problems with reading comprehension despite fluent word decoding. The group of readers are often called poor comprehenders and it has been suggested that as many as $10-15 \%$ of children aged 7-10 may show this profile of reading difficulties (Yuill \& Oakhill, 1991; for reviews see Cain \& Oakhill, 2007; Hulme \& Snowling, 2011; Nation, 2005). However, the prevalence varies between studies. The problems exhibited by this group are not specific to reading comprehension, but rather involve comprehension of oral language in general.

The group of poor comprehenders was initially described by a few British research groups (Nation \& Snowling, 1998a; Yuill \& Oakhill, 1991). In these studies, roughly the same strategy for selecting poor comprehenders has been applied. At 8 or 9 years of age, children were tested on reading accuracy and reading comprehension using the Neale Analysis of Reading Ability (Neale, 1997). In this task, the children 
are asked to read short text passages aloud and answer questions afterwards. The procedure used in the Neale provides a score of the child's reading accuracy, as the tester marks any reading mistakes as they occur. The Neale also provides a score for reading comprehension, based on the scores of literal and inference questions that the children answer after having read the passage. Poor comprehenders are typically identified if they show age adequate reading accuracy and below average reading comprehension skill. For example, Cain and Oakhill (1999) identified a group of poor comprehenders that showed normal word reading accuracy for their age group, but whose performance were at least 6 months below their age group in reading comprehension (19 months on average). Variations of this selection procedure have been used; for example Catts and colleagues (2003) included oral language comprehension in their selection procedure.

Most studies examining poor comprehenders have used crosssectional designs. Thus, relatively few studies have examined precursors of the reading comprehension deficits, especially in the preschool age. In this thesis, that type of study is called retrospective because they go back in time to look for cognitive profiles that might account for subsequent reading comprehension difficulties. Also, only a handful of studies have examined this group of children a couple of years after the problems were first manifested. These studies are called prospective studies as they go forward in time. I will start by describing the cognitive profile of this type of readers from the crosssectional perspective. The cognitive profile includes both difficulties at the word and sentence level and higher-level processes that are needed to create a situation model.

\section{Vocabulary}

As was described earlier in this thesis, studies find a close link between vocabulary and reading comprehension (Ouellette \& Beers, 2009; Torppa, Lyytinen, Erskine, Eklund, \& Lyytinen, 2010). As expected, deficits in vocabulary have been repeatedly found in the group of poor comprehenders (Cain, Oakhill, \& Elbro, 2003; Cain, Oakhill, \& Lemmon, 2004; Catts et al., 2003; 2006 ; Nation, Clarke, Marshall, \& Durand, 2004; Nation, Cocksey, Taylor, \& Bishop, 2010; Nation \& Snowling, 1998b; Stothard \& Hulme, 1992). Nation and colleagues 
have found differences between poor comprehenders and typical readers on various aspects of semantic knowledge (Nation, et al., 2004; Nation \& Snowling, 1998b). For example, they found that a group of 8-9 year old poor comprehenders performed at lower levels on both receptive and expressive vocabulary tasks when compared to a group of typical readers (Nation \& Snowling, 1998b). In the receptive vocabulary tasks the children had to determine which words were synonyms and to understand sayings like "a pat on the back". The expressive vocabulary tasks consisted of defining words and giving multiple contexts of a given word such as bat, which means both an animal and an object used for hitting a ball.

Another aspect of vocabulary concerns the ability to learn new words from text. Cain et al. (2003) compared poor comprehenders to typical readers on the ability to learn new words through reading. They used non-words where the meaning of the words could be inferred from the texts. No differences were found between skilled and less skilled readers when the explanation of the word was immediately following the target word. However, when the explanation and the target word was separated by a number of filler sentences, individuals with reading comprehension problems did significantly worse than the typical readers in defining the words afterwards.

\section{Grammar and morphology}

In addition to vocabulary differences, several studies report further deficits at the word or sentence level for the group of poor comprehenders, namely deficits in grammar and morphology (Catts et al., 2006; Cragg \& Nation, 2006; Nation et al., 2004; Stothard \& Hulme, 1992; Tong, Deacon, Kirby, Cain, \& Parrila, 2011). For example, poor comprehenders and typical readers have been differentiated using the test for reception of grammar (TROG : Bishop, 1983; Stothard \& Hulme, 1992). TROG applies a picture- sentencematching task to examine receptive grammatical understanding.

Morphological awareness refers to the awareness of morphemic structure of words, and the ability to manipulate words to form new words. It has been suggested that the importance of morphological awareness increases over time as the children are exposed to more complex words (Wolter, Wood, \& D'zatko, 2009). Several aspects of morphological awareness have been found to be depressed in poor 
comprehenders. These aspects include weaknesses in inflection of irregular verbs, particularly past tense constructions (Nation, Snowling, \& Clarke, 2005), and difficulties in recalling complex sentences (Nation et al., 2004). Tong and colleagues (2011) found that poor comprehenders had particular weaknesses in understanding derived words but not necessarily inflected words. A derived word is formed based on an existing word; for example unhappy and happiness are derived from happy. An inflected word is a modification of a word to express a different grammatical category such as tense; for example write - wrote. Furthermore, Tong and colleagues (2011) suggested that morphological weaknesses emerge over time in the group of poor comprehenders, as differences were found at grade 5 but not two years earlier. As the language used becomes more complex, the poor comprehenders start having problems.

\section{Verbal Memory}

Early work on poor comprehenders has indicated a general working memory deficit (Yuill \& Oakhill, 1991; Yuill, Oakhill, \& Parkin, 1989). For example, Yuill and colleagues (1989) used a span task where they presented numbers 2, 3 or 4 at a time. The children were asked to read the row of digits aloud and memorize the last digit. The results showed systematic differences between a group of poor comprehenders and typical readers.

However, another possibility regarding poor comprehenders and memory skills is that the deficits are restricted to tasks involving semantic aspects of language. If this were the case, poor comprehenders would be more vulnerable in tasks where high demands are put on oral language skills. Nation, Adams, BowyerCrane and Snowling (1999) examined memory skills in poor comprehenders and used simple and complex tasks on verbal as well as non-verbal material. They found no evidence that poor comprehenders showed lower results compared to typical readers on tasks tapping general working memory. However differences were found in verbal working memory tasks. For instance, poor comprehenders recalled fewer abstract words in a serial recall task. They also did less well on a listening span task. To sum up, there is not enough evidence to suggest a general working memory deficit in poor comprehenders. 


\section{Inferences and other text-related processes}

In order to create a rich representation of a text, a situation model, the reader has to integrate each sentence with the situation model and infer information that is not explicitly expressed in the text (Cain, 2010). The links that establish local coherence are inferences that connect sentences with each other to form a network of relations between propositions. This type of inferences is referred to as text-connecting. In addition, inferences also have to be made from text information to general knowledge of the reader to establish global coherence, socalled gap-filling inferences (Cain, 2010).

Several studies have suggested that poor comprehenders make fewer inferences compared to typical readers (Cain \& Oakhill, 1999; Cain, Oakhill, \& Bryant, 2001; Catts et al., 2006). Cain and Oakhill (1999) used a comprehension-age match design, and they found that a group of poor comprehenders performed significantly worse than a younger group of readers matched on reading comprehension ability on text connecting inferences but not on gap-filling inferences. This pattern suggests that the inference problems exist prior to the reading comprehension problems and is not an effect of the low level of reading comprehension exhibited by the poor comprehenders.

Another complex process involved in creating a situation model is comprehension monitoring. Comprehension monitoring refers to a person's ability to evaluate their comprehension (Cain, 2010). For example, this can entail checking whether a text makes sense and taking actions such as re-reading and generating an inference to recover from comprehension failure. Comprehension monitoring can be assessed by error detection tasks. Not surprisingly, poor comprehenders are often compromised on comprehension monitoring tasks (Cain \& Oakhill, 2003). Relatedly, several studies have found that poor comprehenders have limited knowledge of different text structures. When assessed in narrative tasks, poor comprehenders often produced list-like stories with no obvious goals (Cain, 1996; 2003; Cain \& Oakhill, 1996, Cragg \& Nation, 2006).

\section{Poor comprehenders across time}

Now we turn to the retrospective and prospective studies which have examined poor comprehenders over time. A couple of retrospective studies have examined poor comprehenders prior to any reading 
instruction (Justice, Mashburn, \& Petscher, 2013; Torppa et al., 2007) or as the children are just beginning their reading development (Catts et al., 2006; Nation et al., 2010). While oral language skills appear to be somewhat lower in poor comprehenders at the beginning of language development, differences between typical readers and poor comprehenders were not significant until age 4-5. Catts and colleagues (Catts et al., 2003; 2006) compared poor comprehenders selected in grade 2 or 8 to poor decoders and typical readers. They found depressed results in the poor comprehension group compared to the other groups in kindergarten on a composite of vocabulary, grammar and story comprehension. Also, these differences showed stability across grades. Similar results were obtained in the Nation et al., (2010) study such that the poor comprehenders, selected at age 8 , showed poor performance on oral language skills in kindergarten.

In the prospective perspective, Cain and Oakhill (2006) showed that all but 1 out of 23 poor comprehenders selected at age 8, showed poor reading comprehension performance three years later. At age 11, the poor comprehenders also exhibited depressed results in science and math which indicated a negative educational trend for this group over time.

\section{Within-group variability and interventions}

Do all poor comprehenders show the same cognitive profile, and can we identify core weaknesses in the group of poor comprehenders? Three studies have examined within-group variability among poor comprehenders, and these studies have reported two major findings. First, the studies have found high levels of heterogeneity between poor comprehenders within the same study, as not all poor comprehenders exhibited poor performance on all oral language skills (Cain \& Oakhill, 2006; Cornoldi, de Beni \& Pazzaglia, 1996; Nation et al. 2004). For instance, Cain and Oakhill (2006) found that less than half of the children in their poor comprehender group showed vocabulary below the mean of the entire sample. Second, it is difficult to find a single task where most poor comprehenders show deficits compared to typical readers. The most consistent deficit found in poor comprehenders in a study by Nation et al. (2004) was compromised performance on a sentence recall task, possibly a consequence of poor syntactic knowledge or compromised memory skills. On this task, 11 
out of the 23 poor comprehenders performed significantly below mean of the entire sample.

There is considerable variability in the severity of the deficits reported for poor comprehenders. While most studies report mean values on oral language and cognitive skills in the poor comprehender group that are at sub-clinical levels, Nation and colleagues (2004) reported that $17-35 \%$ of their group of poor comprehenders met criteria for specific language impairment. None of these children had received any special help for their difficulties.

This concludes the section of the thesis which describes the theoretical background of the studies. We now move on to aims of the thesis, methods, a summary of the included studies and finally a general discussion. 


\section{General aims}

Reading comprehension difficulties can occur in children for a variety of reasons. In this thesis, the Simple View of Reading has been used as a theoretical framework to understand difficulties in reading comprehension in school-age children. The general aim of this thesis has been to describe the cognitive and language profile of children with reading comprehension difficulties using a longitudinal perspective. The thesis has especially focused on reading comprehension difficulties in children with adequate decoding skills, from preschool through the first years of school. The specific research questions that have been examined in this thesis are:

- Given that we can define groups that show a specific deficit in one of the sub-skills within the Simple View of Reading (decoding or comprehension), how stable and specific are their deficits across time? (Study I)

- What characterizes children with specific poor reading comprehension compared to children with good reading comprehension? (Study II)

- What are the best preschool predictors of reading comprehension and decoding impairments in grade 2, 4 and $8 / 9$ ? (Study III) 


\section{Methods}

In the methods section, the international longitudinal twin study will be described along with a general description of the selection and translation of tests included in the dataset.

\section{Participants}

The studies in this thesis have used data from the international longitudinal twin study (ILTS) (Byrne et al., 2002; 2005; Samuelsson et al., 2005; Olson et al., 2011). The ILTS includes a population sample of twins, with parallel data collected in four different countries, the US, Australia, Sweden and Norway. The overall aim of this project has been to examine genetic and environmental influences on prereading and early reading skills. To date more than 1000 twin pairs have been included in the study.

The parents of the twin pairs gave written informed consent prior to inclusion in the study. They have also received written and oral information about the study prior to inclusion and at each follow up occasion. No payment was given in the Scandinavian countries or Australia; however in the US the families received a payment of $\$ 100$ for participation.

The logic behind behavior-genetic analyses is to compare correlations of results within and between twin pairs. Monozygogic (MZ) twins share $100 \%$ of their segregating genes and dizygotic (DZ) twins share $50 \%$ of their segregating genes on average. An assumption made is that $\mathrm{MZ}$ and $\mathrm{DZ}$ twins share environment to the same degree. Based on this assumption, greater similarity between MZ twins compared to DZ twins can be attributed to genes, and estimates of heritability can be obtained by calculation of within-pair correlations and co-variances (Neale \& Cardon, 1992). Although the overall aim of the ILTS is to examine behavioral genetic patterns in reading across time, in this thesis behavioral-genetic analyses have not been used. Instead, in this thesis the twins have been treated as individuals rather than twin pairs. Care has been taken so that the fact that the children were twins influenced the results as little as possible. 
The families included in the study are all native speakers of the language of the country that they inhabit. The U.S. sample is a population sample of twins ascertained through the Colorado Twin Registry. This registry contains records of all twin births in Colorado. In the first wave of testing, $86 \%$ of the families that were contacted agreed to participate. For the Scandinavian sample, the twins were ascertained through the Swedish and Norwegian Medical Birth Registry. About $60 \%$ of the families in the first wave of testing agreed to participate.

Assessment of the twins started in preschool, close to the twins' 5th birthday, and follow-up was conducted in kindergarten, grade 1, 2 (in all countries), in grade 4, 8 (in Sweden and the US) and grade 9 (in Norway). The number of children varied somewhat across tests and test occasions, but the dropout rate never exceeded $8 \%$.

\section{Materials}

In the project, assessment starts in preschool, earlier than many previous longitudinal studies. Included in the test battery in preschool were tests assessing cognitive and language skills which are known to correlate with or predict early reading and writing acquisition. An important principle was that each theoretical construct should be assessed using several tasks as reliability is a challenge, especially in young children. The theoretical constructs that were included in preschool was PA, RAN, print knowledge, grammar/morphology, vocabulary and verbal memory. Most of these skills were assessed again during the first years of school, but not at each time point and using fewer tests over time. When the twins started school, tests assessing decoding (words and non-words), spelling, reading comprehension and listening comprehension were included.

All tests that were included in the study were originally in English. Tests derived from the Weschler Preschool and Primary Scale of Intelligence (WPPSI-Revised; Wechsler, 1989) and the Illinois Test of Psycholingusitic Abilities (McCarthy \& Kirk, 1961) have been translated and standardized in Sweden and Norway previously. For all other tests, translations have been made for the purpose of this study. Subtests derived from the Wide Range Assessment of Memory and Learning (WRAML; Adams \& Sheslow, 1990) and tasks measuring RAN and letter recognition from names and sounds required marginal 
work on translation. For the phonological tasks used in preschool, 90 $\%$ of the words were translated without having to change original wording or included pictures. For all preschool tasks, the translated versions were used on 5-year-old children before any twins were included. The means and standard deviations of the test used in the pilot studies were similar to data collected in the US with the exception of tasks measuring print knowledge. This is an effect of early emphasis on reading in the US context.

The ambition when translating the word reading measures was that the words used in Norwegian and Swedish should be as similar as possible, semantically and phonetically, to the English versions. For example the Swedish version of the decoding tasks used words that were familiar to Swedish children, $83 \%$ of the words having the same number of syllables, and $76 \%$ having the same meaning as in the English versions. For the non-words, $50 \%$ of the words were exactly the same as in the English versions. For the remaining words, minor changes (including or deleting a letter) were made in cases were the non-words became actual words in Norwegian or Swedish, or to make the words follow common spelling patterns in the respective language. When translating the reading comprehension tests, care was taken that the versions were as similar to the original versions as possible in content and wording. Naturally, changes in word order had to be made to make the translations valid in the Swedish and Norwegian language. 


\section{Summary of the studies}

Three studies are included in the thesis. The background and aims, methods and results of each will be described briefly below.

\section{Study I}

\section{Background and aim}

The literature on poor decoders is extensive, both concerning precursors, cognitive and language profiles and longitudinal consequences of poor decoding skills. Considerably fewer studies have examined specific poor reading comprehenders that do not show decoding deficits, and particularly so over time and before formal reading instruction (but see Catts et al., 2003; 2006; Nation et al., 2010). Identification of poor comprehenders is surrounded by a number of different complexities including difficulties in measuring reading comprehension in a sensible way across age, and difficulties separating decoding and reading comprehension performance (Keenan et al., 2008; Keenan \& Meenan, 2014). Thus, in this study, oral language comprehension was used instead of reading comprehension for selection of poor comprehenders. Two groups of readers were selected from a population sample $(N=926)$ to be either poor decoders (poor decoding but adequate comprehension) or poor oral comprehenders (poor comprehension but adequate decoding). The deficit groups were identified based on the components presented in the Simple View of Reading, decoding and comprehension (Gough \& Tunmer, 1986). The main question addressed in this study was: Given that we can define poor oral comprehenders and poor decoders, how stable and specific are their deficits?

\section{Method}

In this study, 926 American twins from the international longitudinal twin study were used. Children were tested at preschool (mean age 60 months) in kindergarten, grade 1,2 and 4. At the preschool age a test battery was used which included composites of PA, RAN, print knowledge, vocabulary, grammar/morphology and verbal memory. Across grades, most skills that were assessed in preschool were re- 
assessed at later grades. When the children started school, decoding, reading comprehension and listening comprehension were assessed.

\section{Results and discussion}

At grade 4 , poor decoders $(N=85)$ with adequate oral comprehension and poor oral comprehenders $(N=99)$ with adequate decoding skills were selected based on composites of decoding and oral language. These two groups were compared retrospectively from preschool. The results was consistent with the literature showing decoding-related deficits in the poor decoders (PA, RAN) and oral language weaknesses in the poor oral comprehenders (vocabulary, grammar/morphology, and verbal memory) from kindergarten to grade 4. (e.g., Catts et al., 2006; de Jong \& van der Leij, 2003). However, two findings were unexpected. First, poor decoders exhibited lower reading comprehension compared to poor oral comprehenders in grade 4. This pattern could be explained by the fact that decoding still explains a large amount of variance in reading comprehension in grade 4 . Thus poor decoding continues to put strong constraints on reading comprehension compared to poor oral language at this age. When we controlled for decoding in reading comprehension, we found lower levels of reading comprehension in the poor oral comprehenders in grade 4. The second unexpected finding was that lower levels of PA and print knowledge were found in the group of poor oral comprehenders compared to the poor decoders. A general low oral language profile appears to affect decoding related skills in preschool, before any reading instruction has taken place.

The results were further strengthened by logistic regression analyses predicting poor oral comprehenders and poor decoders. Two predictors influenced the prediction significantly, vocabulary and RAN. As a third step, we examined the significant predictors' usefulness for selection of at-risk groups in preschool. At-risk poor decoders were selected as those with compromised RAN but adequate vocabulary. Likewise, at-risk poor oral comprehenders were selected as those with compromised vocabulary but adequate RAN. Although there were relatively little overlap between the at-risk groups and the groups selected in grade 4, large effect sizes of the differences between groups in decoding and listening comprehension were found in grade 4. 


\section{Study II}

\section{Background and aim}

Unlike typically developing children, some children's reading comprehension does not develop in parallel with their word decoding skills during the first years of school. A number of studies have examined the cognitive and language profile of this group, commonly called poor comprehenders (for reviews see Cain \& Oakhill, 2007; Nation, 2005). These studies have found deficits in a broad range of oral language tasks including vocabulary (Nation et al., 2010) and inference making (Cain et al., 2001). Most of these studies have been limited in the developmental range and in the range of oral language skills that were assessed within the same study.

In this study, the term "Specific Poor Reading Comprehenders" (SPRC) was used because the children show compromised reading comprehension skills that are unexpected based on their more adequate levels of word decoding. The group of SPRC were compared to a group matched for decoding skills that exhibited above mean performance in reading comprehension (good comprehenders). The groups were selected in grade 4 , and examined retrospectively starting in preschool. The main question addressed was: What characterized children in the SPRC group compared to good reading comprehenders?

\section{Methods}

In preschool, 6 composites were used (PA, RAN, print knowledge, grammar/morphology, vocabulary and verbal memory) along with a single task of non-verbal IQ. In kindergarten, grades 1, 2 and 4 some of the skills assessed in preschool were assessed again, and after the twins had started school reading, spelling, reading comprehension and listening comprehension skills were assessed.

\section{Results and discussion}

The SPRC group $(N=56)$ were selected using composites of reading comprehension and decoding at grade 4, and using three criteria; reading comprehension below -.67 SD, decoding above -.67 SD, and a discrepancy between the two measures of at least $.67 S D$. This procedure has previously been used by Nation and colleagues (2010). The children in the good comprehender group showed reading 
comprehension results above the mean of the entire sample and they were individually matched on decoding skills with the SPRC.

The results showed a remarkable consistency in relation to the group selection in grade 4 in decoding and spelling. Differences in reading comprehension were significant at all test occasions (grades 1, 2 and 4) but the differences were much larger in grade 4 . These patterns of results were in line with the concept of late emerging reading comprehension deficits (Catts, Compton, Tomblin, \& Bridges, 2012).

The SPRC showed a developmentally consistent poor oral language profile indicated by depressed results in grammar, vocabulary, and verbal memory at all measurement occasions. For these three oral language measures, more than $23 \%$ of the sample showed severe deficits $(<-1 S D)$ and more than $70 \%$ showed performance below the mean of the full sample. The profile of the SPRC also included low levels of PA, print knowledge and non-verbal IQ in preschool and compromised listening comprehension in grade 4. Contrary to previous studies examining within-group variability of SPRC (Cain \& Oakhill, 2006; Cornoldi et al., 1996; Nation et al., 2004), we found a homogeneous profile of oral language deficits across grades for the group of SPRC.

\section{Study III}

\section{Background and aim}

Early identification is of great importance as early targeted intervention strategies can reduce associated problems in young readers. A large body of literature has examined early cognitive and language profiles of children who will later show decoding deficits. Considerably fewer studies have examined early predictors of reading comprehension impairment and especially in the long perspective (but see Adlof et al., 2010; Badian, 2001; Frost et al., 2005). These studies have suggested a developmental shift in prediction of reading comprehension from early school age to adolescence, but the pattern differs between studies.

The orthographic depth of a language refers to how easy it is to decode based on letter-sound correspondences. A transparent language, such as Swedish and Norwegian, has many one to one letter phoneme correspondences which make the words easy to predict based on its 
spelling. An opaque language, such as English, has many unusual or irregular pronunciations. This means that the irregular pronunciations have to be memorized to achieve successful decoding. As none of the prediction studies presented above have been performed in a transparent orthography it is not clear how the results generalize to a transparent context. A number of studies have implied that early prediction patterns differ depending on regularity of orthography (e.g. Caravolas et al., 2012).

In this study, a Swedish and a Norwegian twin sample was used to predict impairment in reading comprehension and decoding across a time period of 10 years. Predictions were made from preschool to grade 2, 4 and 8/9. The question that we addressed was: What are the best preschool predictors of reading comprehension and decoding in grade 2,4 and $8 / 9$ ?

\section{Methods}

The Swedish and Norwegian samples of twins from the ILTS were used in the present study. The data were collected in preschool and grade $2(N=550)$ in both countries, in grade 4 and 8 in Sweden $(\mathrm{N}=$ 201 and $N=48$ respectively) and in grade 9 in Norway $(N=103)$. The grade 8 and 9 data were combined in the analyses. In preschool, six composites were used for predictions; these were PA, RAN, print knowledge, vocabulary, grammar/morphology and verbal memory. In addition, a single measure of non-verbal IQ was used. For the reading assessments, a speeded decoding task (TOWRE; Torgesen, Wagner \& Rashotte, 1999) was used assessing both words and non-words across test occasions. For reading comprehension, the Woodcock Passage Comprehension test (Woodcock, 1987) was used at all test occasions. In grade 4 and 8/9 the Gates MacGinitie Reading Comprehension of Passages (MacGinitie \& MacGinitie, 1989) was added as an additional reading comprehension task. These two skills formed a reading comprehension composite in grades 4 and 8/9.

\section{Results and discussion}

A cut-off of - $1 S D$ was used to select the children who performed in the low tail in reading comprehension and decoding in grade 2, 4 and 8/9. In line with our expectations, the prediction patterns changed for reading comprehension. 
Verbal memory was a significant predictor of reading comprehension impairments at all test occasions. In grade 2 additional predictors were print knowledge and non-verbal IQ. In grade 4, print knowledge and grammar/morphology made significant contributions. In grade 8/9 RAN made an important contribution to prediction of reading comprehension impairment.

RAN was a statistically significant predictor of decoding impairment at all test occasions and print knowledge contributed significantly at grade 2 . The results emphasize the importance of verbal memory tasks and RAN in prediction of reading impairment, over short or long periods of time. The importance of RAN in this study could be partly attributed to the fact that the study was done in a transparent orthography (Landerl \& Wimmer, 2000).

\section{Summary of findings}

In the first study we examined stability and specificity of language deficits in groups selected with a specific deficit in one of the subcomponents of the Simple View of Reading (decoding or comprehension). We found high levels of stability in compromised oral language skills such as vocabulary, grammar and verbal memory across all test occasions for the poor oral comprehenders. Likewise, poor decoders showed a generally low profile in PA, print knowledge, RAN, decoding and spelling, across time. However, deficits in PA and print knowledge found in preschool were not specific to the poor decoder profile. Rather, they could be seen as part of an oral language deficit in the poor oral comprehenders, before school entry. Also, reading comprehension deficits were stable in the group of poor decoders across all test occasions. However, for children with oral language deficits, the problems in reading comprehension began to emerge in grade 4.

In study II, we examined specific poor reading comprehenders (SPRC) and asked the question: What characterized children with specific poor reading comprehension compared to good reading comprehenders? Again, we found that an oral language deficit characterized many of the SPRC across time. The profile of the SPRC included compromised grammar, vocabulary and verbal memory across time. At age 5, the profile also included compromised PA, print knowledge and non-verbal IQ, and in grade 4 listening comprehension. 
In contrast to previous studies a homogeneous profile was found, as many of the SPRC exhibited at least mild, but often severe, deficits in oral language skills.

In study III we examined which of the preschool composites that explained variance in prediction of reading comprehension and decoding impairments in grade 2, 4 and 8 . We found that the predictors changed across time for both decoding and reading comprehension. For decoding, predictors changed from decoding-related (print knowledge) to fluency-related skills (RAN). For prediction of reading comprehension impairment, verbal memory was significant at all test occasions. For additional predictors the same pattern found for decoding was found for reading comprehension such that significant predictors changed from decoding- to fluency-related predictors. 


\section{Discussion}

In the last 40 years, there has been significant progress in understanding reading difficulties. For children with decoding deficits research has been very successful in establishing identification procedures and targets for intervention (Ehri et al., 2001; Stanovich, 1986; Stanovich \& Siegel, 1994; Vellutino et al., 2004). However, for children who exhibit difficulties in comprehension much less is known about causes, how children can be identified early in development and what type of teaching is most effective.

The aim of this thesis has been to describe the cognitive and language profiles of children with reading comprehension difficulties using a longitudinal perspective. The Simple View of Reading (Gough \& Tunmer, 1986) has been used as a starting point for subtype selection. The framework has previously been used to classify different types of poor readers (Aaron et al., 1999; Catts et al., 2003). The general idea is that children who exhibit poor reading comprehension either show impairment in one of the components (decoding and comprehension) or in both components. In Study I, children with specific deficits in one of the two dimensions of the simple view were contrasted. With this contrast the development of reading comprehension could be examined in two different subtypes who are at-risk of developing reading comprehension difficulties. In Study II, poor reading comprehenders were selected based on a common procedure; selection of specific poor reading comprehenders with adequate decoding (SPRC). The SPRC were compared to good comprehenders. In Study III, all individuals who showed poor reading comprehension, that is a general poor reading comprehension profile, were selected at three different occasions and compared to the rest of the sample. Based on these three studies, the language profiles of the subtypes of poor reading comprehenders in oral language and decoding-related skills will be discussed. The discussion consists of five different sections. In the first section, the early language profiles of the different subtypes are discussed across studies. The second part covers reading comprehension deficits, and especially when they are apparent in different subtypes. Some methodological limitations and 
educational implications are discussed in the subsequent two sections. The general discussion ends with some suggestions for future research.

\section{Early language profiles}

Oral language deficits were found in the poor oral comprehenders (Study I) and SPRC (Study II) in vocabulary, grammar, verbal memory and listening comprehension. This is consistent with previous research showing impairments starting from around age 4-5 in grammar and vocabulary (Catts et al., 2006; Justice et al., 2013; Nation et al., 2010; Torppa et al., 2007). The results of this thesis extend previous studies by showing longitudinal stability in poor oral language skills over many years, and by showing a deficit in verbal memory. Also, previous studies examining within-group variability have suggested a heterogeneous profile in groups of poor comprehenders (Cain \& Oakhill, 2006; Nation et al., 2004). Thus, the findings of this thesis are not consistent with this research. Instead in this thesis, aspects such as vocabulary, grammar/morphology, verbal memory and listening comprehension qualify to be called "core deficits" of poor comprehenders. Differences between Study II and the studies reporting relative heterogeneity within profiles may be a consequence of task demands of the reading comprehension test used for selection or age of the children (Keenan et al., 2008; Keenan \& Meenan, 2014). Research has shown that vocabulary is more influential in reading comprehension later in the development (de Jong \& Leij, 2002; Torgesen et al., 1997). Selection of groups of poor comprehenders were done relatively late in this thesis compared to other studies and using a different set of tests compared to the commonly used Neale Analysis of Reading Ability (Neale, 1997). The partly different results obtained in this thesis can possibly be attributed to these differences.

In this thesis, robust memory deficits were found in all subtypes with comprehension difficulties. Also, verbal memory contributed to explaining reading comprehension impairments in grades 2, 4 and 8/9 in the logistic regression analyses in Study III. The role of different aspects of memory in reading comprehension has been debated. Working memory deficits have been found in some groups of poor comprehenders (Yuill \& Oakhill, 1991; Yuill et al., 1989; but see Nation et al., 1999) and compromised working memory could potentially underlie difficulties in reading comprehension (Perfetti et 
al., 1996). In addition, a study by Gathercole, Willis, Emslie and Baddeley (1992) suggested that phonological memory, measured with non-word repetition tasks, can be causally implicated in early vocabulary development. However, several studies have failed to replicate the pattern of results obtained by Gathercole and colleagues (de Jong \& Olson, 2004; Melby-Lervåg et al., 2012). Obviously, the designs used in this thesis do not allow examination of causal relationships between memory and language. Instead we have conceptualized memory aspects as a part of the oral language domain. Our results also give support to this procedure as verbal memory was highly correlated with other oral language skills.

Common for all subtypes of poor reading (or oral) comprehenders in this thesis, selected in grades 2 and 4, was print knowledge deficits. Low levels of PA in preschool also characterized several of our subtypes; poor decoders, poor oral comprehenders and SPRC (Study I and Study II). Thus, it appears that a general low oral language profile can comprise low levels of PA and print knowledge before formal reading instruction (see also Bishop, McDonald, Bird, \& HayiouThomas, 2009; Metsala \& Walley, 1998). The results of this thesis have shown that at preschool, all language skills were highly correlated and a clear distinction between phonological processing skills on the one hand and other oral language skills on the other hand, can be seen only after decoding skills have been established (see also Kendeou et al., 2009). In Study I clear dissociations could be seen in the poor decoders and poor oral comprehenders in PA once they had received some reading instruction. At this time poor oral comprehenders caught up with the level of the full sample in PA. However, the poor decoders did not respond to initial reading instruction in the same way, since their primary deficit lies in phonological processing. Thus, our data suggest that PA and print knowledge assessed at age 5 should be seen as an expression of an oral language core rather than phonological processing skills separated from other types of oral language.

The role of RAN within this thesis is in line with previous research suggesting that RAN is one of the best predictors of reading fluency (Norton \& Wolf, 2012). Slow RAN clearly separated poor decoders from poor oral comprehension in preschool (Study I). Also, slow RAN was consistently associated with prediction of decoding impairments in grades 2, 4, and 8/9 and with reading comprehension impairments in grade 8/9 (Study III). In fact, RAN was the one factor 
that showed relative independence from what has previously been described in this discussion as an oral language core at 5 years of age. Since RAN is relatively independent of skills within the oral language core (for example PA) these results can be seen as support for the double-deficit hypothesis (Wolf \& Bowers, 1999). Also, RAN explains unique variance in predicting future reading problems in decoding and reading comprehension (Study III).

In this thesis, a retrospective perspective has primarily been used. These types of analyses provide useful information about the cognitive profile of different subtypes of readers at earlier test occasions. However, the retrospective design does not control for false positives. Consequently, there may be children who exhibit the same type of difficulties as our subtypes but who will not show reading (or oral) comprehension deficits later in development. This is important to keep in mind while reading the results presented in this thesis. However, in Study 1, we did use a prospective analysis in addition to the retrospective one. Thus, we selected groups at-risk for showing poor oral comprehender and poor decoder profiles based on our results from the retrospective analysis and the two best predictors (RAN and vocabulary). This study showed quite low levels of overlap between at risk and deficit groups in grade 4 (27\% and $37 \%$ for the poor decoders and poor oral comprehenders respectively). But the effect sizes of the comparisons between at-risk groups in grade 4 were impressive (Cohen's $d=.72$ and $d=.49$ for listening comprehension and decoding respectively) given the long time period of 5 years. Although our results help to inform about a pattern of language profiles over time, it is not reasonable to use this type of procedure for early identification and special interventions as the hit rates are still too low. This will be discussed in the section "Educational Implications".

\section{Deficits in reading comprehension}

Decoding deficits are commonly manifested soon after reading instruction has been introduced in school (e.g., Snowling, 2000). However, this thesis supports the concept of late emerging reading difficulties for children with problems associated with comprehension (see also, Leach, Scarborough, \& Rescorla, 2003; Catts et al., 2012). In Study I, the poor oral comprehenders showed a decrease in reading comprehension compared to the mean of the full sample between the 
grades 2 and 4. In addition, the SPRC (Study II) showed quite modest deficits in terms of mean values in grades 1 and 2 compared to the robust reading comprehension deficits obtained in grade 4. In Study III, verbal memory came out as the strongest predictor of reading comprehension impairments in grade 8/9, which suggests that the cognitive deficit profile for the children in the low tail changed from more decoding-related difficulties to more oral language-related difficulties. Are the reported results an expression of the changing nature of reading comprehension (Gough et al., 1996)? Or are the results merely a consequence of the tests that we have applied? We have used the Woodcock Passage Comprehension test (Woodcock, 1987) in Study I and Woodcock Passage Comprehension Test combined with the Gates McGinitie reading comprehension of passages (McGinitie \& McGinitie, 1989) in Study II and III (in grades 4 and beyond). The Woodcock Passage Comprehension Test has been shown to be highly dependent on decoding, especially so in grade 2 (Keenan et al., 2008). Thus, it could be that the reading comprehension deficits found in poor oral comprehenders and SPRC would have been present in grade 2 if we had used a different reading comprehension test. However, the results of this thesis are very much in line with a study by Catts and colleagues (2012) examining late-emergent poor readers. They found that about $13 \%$ of children showed reading disabilities that were not apparent until grade 4 . More than half of these children exhibited difficulties in comprehension. They further suggested that developmental language problems, such as low levels of vocabulary, grammatical knowledge and narrative skills, were underlying the reading difficulties. These results correspond nicely to the pattern of results that have been presented in this thesis.

To sum up, the present thesis gives support to the concept of late emergent poor readers. As the emphasis in school during the first couple of years is often on teaching children how to decode and become fluent readers, limited attention is allocated to comprehension instruction in the early grades. Some children with oral language difficulties do well in early decoding but their oral language deficit influences their reading at later grades. As Catts and colleagues (2012) point out, their difficulties are only late emergent in their literacy development, as the oral language problems can be identified much earlier. In a sense their difficulties are late identified rather than late emergent. 


\section{Methodological Limitations}

The methodological limitations that will be focused in the following section includes statistical effects of selecting groups that exhibit extreme scores on some variable and effects of including twins in statistical analyses.

\section{Selection of extreme groups}

Often individuals with extreme scores on some variable are of interest in different studies, and therefore individuals performing in the low or high tail of the distribution are selected based on a cut off score on a variable of interest. There are a number of controversies surrounding selection of groups, for instance the cut off score can be seen as arbitrary. Also, dissection of continual data can be associated with a number of additional statistical problems (Preacher, Rucker, MacCallum, \& Nicewander, 2005). With extreme group selections, individual differences are reduced to a binary variable. Thus, individual differences within groups are ignored and there is an assumption of homogeneity within groups (Preacher et al., 2005). Using extreme groups can also lead to inflated standardized effect sizes. In addition, the reliability of the measures can be reduced compared to estimates for the population (Preacher et al., 2005).

In this thesis, a subgroup approach was used in part because the results would be more clearly communicated and transferred to educational practice. Research suggests that poor comprehenders are seldom recognized in the classroom (Yuill \& Oakhill, 1991). Yet, this thesis and other studies have shown that poor comprehenders exhibit serious deficits that will most likely influence their future education (e.g., Cain \& Oakhill, 2006). Also, the subgroup of poor comprehenders has not been studied in Sweden previously. Selecting extreme groups in reading comprehension has the following benefits: First, descriptions of a cognitive and language profile of a group of children provide educators with a model to recognize children with similar profiles in their classrooms; second, examinations of subtypes can suggest useful targets for intervention. These aspects are not as clearly communicated when using continuous data.

As mentioned above, reliability is an issue when using extreme groups (Preacher et al., 2005). In the ILTS, care has been taken to assess each construct using several measurements when possible. This 
is particularly important in young children, where reliability is a challenge. By using several tasks assessing the same construct, it is likely that the reliability for each construct is boosted. Hopefully, this approach reduces reliability inflations suggested for selection of extreme groups.

\section{Including twins in statistical analyses}

Often data collected on human beings are clustered such that some individuals within a sample are more similar to each other compared to individuals picked at random from a population. Examples of clustered data can be members of family, pupils in the same class and, of course, twins. An assumption made in inferential statistics is that all observations should be independent of all other observations. When clustered data are used and not included in the statistical model this assumption is threatened. One effect can be that standard errors are underestimated. In essence, each observation contains less unique information and the effective sample size is reduced (Chen, Knok, Luo, \& Willson, 2010). In this thesis, these aspects have been taken into consideration in different ways. In Study I, the groups were selected using one of the twins within a pair selected at random. All analyses were run and compared to analyses on the full sample. As the results were virtually identical we decided to include the full sample in the presented results. In Study II, SPRC and good comprehenders were selected. If both twins were selected in the procedure, one of them was removed from the group. Thereby the analysis was not inflated by intra-class correlations. In Study III, our sample size was limited compared to the other two studies. Therefore we could not reduce our sample size by half, and thus all twins were included in the analyses. This procedure could have influenced the results obtained in the analysis, however on several occasions within the international twin study (see also Study I), running analyses on one twin only on the same variables has yielded very similar results compared to using the full sample (Samuelsson et al., 2005). Therefore it is likely that the effects of including both twins in Study III had relatively minor influence on the results. 


\section{Educational implications}

Two out of the three studies in this thesis were conducted using data collected in the US. A relevant question to ask is whether the results can be generalized to a Swedish school context. Two differences between the countries and languages are worth mentioning. In the U.S., as in many English-speaking countries, informal teaching of reading skills is encouraged in homes and preschools (Mann \& Wimmer, 2002). This is not the case in Sweden where the established view is that formal reading instruction should wait until grade 1 . In the kindergarten year, children in Sweden learn about letter names and sounds. Furthermore, as has been mentioned previously in this thesis, English is an opaque orthography whereas Swedish and Norwegian is much more transparent. Despite these differences, many aspects of early reading development are quite similar in the two contexts. Several studies within the ILTS have examined differences across countries and languages and these studies suggest mostly commonalities in pattern of results across country. When examined at age 5, the twin correlations were very similar across country. Also, the phenotypic correlations on four composite variables measuring early cognitive and language skills were nearly identical across countries. Predictive relationships from preschool and kindergarten to future decoding and spelling skills have also been found to be very similar across countries (Furnes \& Samuelsson, 2009; 2011). However, Samuelsson and colleagues (2005) found differences in mean levels in print knowledge between the U.S. and the Scandinavian sample which can be explained by differences in the age of literacy instruction. Another minor difference has been reported when examining poor decoders. A study by Furnes and Samuelsson (2010) found that PA influenced reading performance for a somewhat shorter period of time in Scandinavian poor readers compared to poor readers from the U.S. and Australia. Thus, the results of these studies suggest that despite small differences, the general relationship between early cognitive and language skills appear to be the same across countries. Therefore it is very likely that the results from the studies conducted on U.S. data are generalizable to a Swedish context. 


\section{Language profiles and teaching}

The most robust result in this thesis is that a widespread oral language deficit was found in children who were at-risk of developing reading comprehension deficits. The profile included compromised vocabulary, grammar, verbal memory and listening comprehension. The oral language deficit showed high levels of stability across time, and interacted with reading-related skills in different ways. For example, prior to reading instruction the oral language deficits were manifested as low levels of PA and print knowledge in the children atrisk for reading comprehension deficits. Also, early reading performance may be at age-appropriate levels in the primary grades, but reading comprehension will most likely be depressed later and influence future educational achievements.

In Sweden, an early phonological training program, Bornholmsmodellen, has received wide-spread support and is used in preschool and kindergarten classrooms across the country. Phonological training programs have been shown to be helpful for children at risk of becoming poor decoders (Bradley \& Bryant, 1983; Ehri et al., 2001; Lundberg et al., 1998). The studies in this thesis have showed that some children may, despite low levels of phonological skills, exhibit normal decoding development. However, their poor oral language skills will later influence reading comprehension. For these children, it is likely that interventions supporting general oral language skills would be beneficial. The widespread oral language deficit found in the different groups of children showing comprehension-related difficulties in this thesis provides many opportunities for interventions as it involves vocabulary, grammar, verbal memory and listening comprehension. However, interventions in vocabulary have shown robust effects on reading comprehension (Beck, Perfetti, \& McKeown, 1982; Clarke et al., 2010). A lot of evidence suggests that vocabulary interventions should be made as early as possible (Biemiller \& Boote, 2006; Biemiller \& Slonim, 2001; National Reading Panel, 2000). This is important as differences between children in vocabulary knowledge tend to expand over time and it has been suggested that children with a large vocabulary more easily learn new words (Hart \& Risley, 2003).

The results of this thesis have shown specificity and stability starting at age 5 in oral language weaknesses in children who will later show comprehension based difficulties. However, this does not 
necessarily mean that children can be identified in an easy way at this early age. Some children may show a compromised language profile in preschool and end up having a normal development in reading. Therefore, identification of subgroups which will be provided with extra support is not advisable, as the hit rate is still relatively low. Rather, based on the results of studies examining preschool skills and early reading, educational practice should set an agenda to boost all children's oral language skills from an early age. Formal instruction of word meaning is necessary in preschool and school practice and is especially important for those children whose oral language skills are below age-appropriate levels (Beck et al., 1982; Biemiller \& Boote, 2006; Stahl \& Fairbanks, 1986). Also, children should practice listening comprehension, as this thesis and other studies (e.g., Catts et al., 2012) suggest that not enough attention is allocated to practicing comprehension during the preschool and early school years.

\section{Reading comprehension}

That reading comprehension is a multifaceted skill needs to be recognized in educational practice. Early work on poor comprehenders have suggested that the difficulties were seldom recognized in the classroom (Yuill \& Oakhill, 1991). This thesis suggests that reading comprehension difficulties in children with adequate decoding skills are late emerging, such that they were not apparent until grade 4 (see also Catts et al., 2012; Leach et al., 2003). Therefore, reading comprehension should be assessed continually during the school years. Research has also shown complexities with regard to reading comprehension tests (Keenan et al., 2008; Keenan \& Meenan, 2014). Therefore assessment of reading comprehension should be thorough and involve both standardized tests and informal assessments in the classroom. Cain (2012) suggests that reading comprehension should be assessed using words, sentences and longer passages. If possible, assessments should also involve listening comprehension tasks. The results of the assessments should be used wisely to guide teaching in groups and individuals. If assessments and instruction in comprehension is used systematically during the first years of school, hopefully the number of children with late emerging reading problems will be reduced. 


\section{Suggestions for future research}

This thesis has given some information about cognitive and language skills in children with comprehension-related disabilities over the first school years. However, as this area has received relatively little attention in reading research previously, there are many areas where research is lacking. In this section, three different areas for future research will be suggested.

As discussed above in the section "Educational implications," it is likely that the results of the two studies conducted on American children are transferrable to a Swedish context. Nevertheless, groups of poor comprehenders have not been identified and examined in Sweden. Therefore, it is an important task for future research to examine this subtype both within different types of orthographies and within different school systems to examine if the results are similar across countries as well as orthographies.

Some studies involving poor comprehenders suggest that the difficulties may be most emphasized in higher-level-order skills such as making inferences and monitoring reading (Cain et al., 2001). Others, as the studies in this thesis, suggest that the difficulties may be more fundamental and involve basic level skills (Adlof et al., 2010; Nation et al., 2010). Few studies have examined the coordination of lower level and higher level skills in reading comprehension, especially in poor reading comprehenders. Understanding more about the process of reading comprehension is important. One example would be to examine how oral language skills such as vocabulary contribute to higher-level skills such as inference making.

To date there is a widespread emphasis on reading comprehension instruction in Sweden, a consequence of depressed results in reading comprehension tests in international studies. Established reading comprehension programs such as Reciprocal Teaching (Palinscar \& Brown, 1984), Concept-Oriented Reading Instruction (Guthrie et al., 2004), Transactional Strategies Instruction (Brown, Pressley, van Meeter, \& Schuder, 1996) and Questioning the Author (Beck, McKeown, Sandora, Kucan, \& Worthy, 1996) are made much more approachable for teachers in Sweden (Westlund, 2009). The aim of these programs is to teach reading strategies to children. These programs have shown robust effects on reading comprehension skills in classrooms. To date, few studies have examined interventions that 
are targeted to children with specific poor reading comprehension. Extensive research is needed concerning the content, methods and procedures at different ages that are most effective in supporting children with or at risk for developing reading comprehension problems. 


\section{Acknowledgements}

A long project has come to an end. The journey has provided its fair amount of ups and downs and I have come out on the other side, not quite the same as I was when I started the project. I have learned a lot, about myself, about statistics, teaching, academic writing and not least reading research. There are a number of people who have contributed to this work in different ways, and I want to express my warmest gratitude towards them.

First of all, thanks to my supervisors! Stefan Samuelsson, your ability to inspire and your sharp eye for what the core is and how it should be communicated has really been invaluable throughout the process. Also, thank you for your generosity with your knowledge and for sharing your extensive network which has created many opportunities for me. Stefan Gustafson, who came in at the end of the process, thank you for helping me with realistic take on writing a $\mathrm{Ph}$. $\mathrm{D}$, and getting it done! To both of you thanks for stimulating and fun conversations on all topics!

Also, I owe a great thanks to my colleagues working in the international twin study in the U.S., Australia and Norway. Dick Olson, Janice Keenan and Brian Byrne, your extremely sharp minds and high standards has really improved the quality of the papers and taught me a lot about academic writing and reading research. Thanks for all the hard work that you put in! Also, thanks to Dick for allowing me to use the American twin data for my analyses. Bjarte Furnes, thank you for contributing with helpful knowledge on regression studies among other things on the third manuscript.

I also wish to express my warmest thanks to Christina Wiklund and Inger Fridolfsson working in the twin project in Linköping. Thank you for good collaboration over the years and for sharing positive energy and knowledge about the real world of reading instruction with me.

Teaching has been an important part of my $\mathrm{Ph}$. D education and the transition from being a rookie to a relatively confident course coordinator would not have been so smooth without the excellent support of experienced colleagues. I would like to express my gratitude to the great teachers that I have collaborated with throughout the years, 
especially Anna-Lena Eriksson Gustavsson and Karin Forslund Frykedal, Thank you for sharing your expertise with me and for making teaching inspiring and fun!

Last but not least, I would like to thank dear colleagues and friends at PEDI, especially Christina Aminoff and Pether Sundström, and my family. Thank you for contributing to my work in all sorts of ways!

Linköping, August, 2014

Åsa Elwér 


\section{References}

Aarnoutse, C., van Leeuwe, J., \& Verhoeven, L. (2005). Early literacy from a longitudinal perspective. Educational Research and Evaluation, 11, 253-275.

Aaron, P. G., Joshi, M., \& Williams, K. A. (1999). Not all reading disabilities are alike. Journal of Learning disabilities, 32, 120-137.

Adams, M. J. (1990). Beginning to read: Thinking and learning about print. Cambridge, Mass.: MIT Press.

Adams, W., \& Sheslow, D. (1990). Wide Range Assessment of Memory and Learning. Wilmington, DE: Jastak Associates.

Adlof, S. M., Catts, H. W., \& Lee, J. (2010). Kindergarten predictors of second versus eighth grade reading comprehension impairments. Journal of Learning Disabilities, 43, 332-45.

Akmajian, A., Demers, R. A., Farmer, A. K., \& Harnish, R. M. (1995). Linguistics: An introduction to language and communication. (4. ed.). Cambridge, Mass.: MIT Press.

Al Otaiba, S., Kosanovich M. L., \& Torgesen, J. K., (2012). Assessment and instruction for phonemic awareness and word recognition skills. In A. G. Kahmi \& H. W. Catts (Eds.), Language and reading disabilities (3rd ed.) (pp. 112-145). Boston: Pearson.

Anderson, R. C., \& Freebody, P. (1981). Vocabulary knowledge. In J. Guthrie (Ed.), Comprehension and teaching: research reviews (pp. 77-117). Newark, DE: International Reading Association.

Baddeley, A. D., \& Hitch, G. J. (1974). Working memory. In G. Bower (Ed.), Recent advances in learning and motivation (pp. 4790). New York: Academic Press.

Badian, N. (2001). Phonological and orthographic processing: Their roles in reading prediction. Annals of Dyslexia, 51, 179-202.

Beck, L., McKeown, M. G., Sandora, C., Kucan, L., \& Worthy, J. (1996). Questioning the author: A yearlong classroom implementation to engage students with text. Elementary School Journal, 96, 385-414.

Beck, I. L., Perfetti, C. A., \& McKeown, M. G. (1982). The effect of long term vocabulary instruction on lexical access and reading comprehension. Journal of Educational Psychology, 74, 506-521. 
Biemiller, A., \& Boote, C. (2006). An effective method for building meaning vocabulary in primary grades. Journal of Educational Psychology, 98, 44-62.

Biemiller, A., \& Slonim, N. (2001). Estimating root word vocabulary growth in normative and advantaged populations: Evidence for a common sequence of vocabulary acquisition. Journal of Educational Psychology, 93, 498-520.

Bishop, D. (1989). Test for Reception of Grammar (TROG) (2nd ed.). Abingdon, UK: Medical Research Council.

Bishop, D. V. M., \& Adams, C. (1990). A prospective study of the relationship between specific language impairment, phonological disorders and reading retardation. Journal of Child Psychology and Psychiatry, 31, 1027-1050.

Bishop, D. V. M., McDonald, D., Bird S., Hayiou-Thomas, M. E (2009). Children who read words accurately despite language impairment: Who are they and how do they do it? Child Development, 80, 593-605.

Bloodgood, J. (1999). What's in a name? Children's name writing and name acquisition. Reading Research Quarterly, 34, 342-367.

Bowers, P. G. (1995). Tracing symbol naming speed's unique contribution to reading disabilities over time. Reading and Writing, 7, 189-216.

Bowey, J. A. (1986). Syntactic awareness in relation to reading skill and ongoing reading comprehension monitoring. Journal of Experimental Child Psychology, 41, 282-299.

Bradley, L., \& Bryant, P. E. (1983); Categorizing sounds and learning to read - A causal connection. Nature, 301, 419-421.

Brown, R., Pressley, M., Van Meter, P., \& Schuder, T. (1996). A quasi-experimental validation of transactional strategies instruction with low-achieving second-grade readers. Journal of Educational Psychology, 88, 18-37.

Bruck, M. (1990). Word-recognition skills of adults with childhood diagnoses of dyslexia. Developmental Psychology. 26, 439-445.

Bus, A. G., \& van IJzendoorn, M. H. (1999). Phonological awareness and early reading: A meta-analysis of experimental training studies. Journal of Educational Psychology, 91, 403-414.

Byrne, B., Delaland, C., Fielding-Barnsley, R., Quain, P., Samuelsson, S., Hoien, T., ...\& Olson, R. K. (2002). Longitudinal twin study of 
early reading development in three countries: Preliminary results. Annals of Dyslexia, 52, 49-74

Byrne, B., \& Fielding Barnsley, R. (1993). Evaluation of a program to teach phonemic awareness to young children: A 1-year follow-up. Journal of Educational Psychology, 85, 104-111.

Byrne, B., Wadsworth, S., Corley, R., Samuelsson, S., Quain, P., DeFries J. C.,... \& Olson, R. K. (2005). Longitudinal twin study of early literacy development: Preschool and kindergarten phases. Scientific Studies of Reading, 9, 219-235.

Cain, K. (1996). Story knowledge and comprehension skill. In C. Cornoldi \& J. Oakhill (Eds.), Reading comprehension difficulties: Processes and remediation (pp. 167-192). Mahwah, NJ: Lawrence Erlbaum Associates.

Cain, K. (2003). Text comprehension and its relation to coherence and cohsion in children's fictional narratives. British Journal of Developmental Psychology, 21, 335-351.

Cain, K. (2007). Syntactic awareness and reading ability: Is there any evidence for a special relationship? Applied Psycholinguistics, 28, 679-694.

Cain, K. (2010). Reading development and difficulties. Chichester, West Sussex, U.K.: BPS Blackwell/John Wiley.

Cain, K., \& Oakhill, J. (1996). The nature of the relationship between comprehension skill and the ability to tell a story. British Journal of Developmental Psychology, 14, 187-201

Cain, K. \& Oakhill, J. (1999). Inference making ability and its relation to comprehension failure. Reading and Writing, 11, 489-503.

Cain, K., \& Oakhill, J. (2003). Reading comprehension difficulties. In T. Nunes \& P. Bryant (Eds.). Handbook of children's literacy (pp. 313-318). The Netherlands: Kluwer

Cain, K., \& Oakhill, J. (2006). Profiles of children with specific reading comprehension difficulties. The British Journal of Educational Psychology, 76, 683-96.

Cain, K., \& Oakhill, J. (2007). Reading comprehension difficulties: Correlates, causes and consequences. In C. Cain \& J. Oakhill (Eds), Children's comprehension problems in oral and written language: A cognitive perspective. New York, NY: Guildford.

Cain, K., Oakhill, J. V, \& Bryant, P. E. (2001). Comprehension skill , inference-making ability, and their relation to knowledge. Memory \& Cognition, 29, 850-859. 
Cain, K., Oakhill, J. V., \& Elbro, C. (2003). The ability to learn new word meanings from context by school-age children with and without language comprehension difficulties. Journal of Child Language, 30, 681-694.

Cain, K., Oakhill, J., \& Lemmon, K. (2004). Individual differences in the inference of word meanings from context: The influence of reading comprehension, vocabulary knowledge, and memory capacity. Journal of Educational Psychology, 96, 671-681.

Caravolas, M., Lervåg, A., Mousikou, P., Efrim, C., Litavsky, M., Onochie-Quintanilla, E., ... Hulme, C. (2012). Common patterns of prediction of literacy development in different alphabetic orthographies. Psychological Science, 23, 678-686.

Cardoso-Martins, C., \& Pennington, B. (2004). The relationship between phoneme awareness and rapid serial naming skills and literacy acquisition: The role of developmental period and reading ability. Scientific Studies of Reading, 8, 27-52.

Castles, A., \& Coltheart, M. (2004). Is there a causal link from phonological awareness to success in learning to read? Cognition, 91, 77-111.

Catts, H., Adlof, S., \& Weismer, S. (2006). Language deficits in poor comprehenders: A case for the simple view of reading. Journal of Speech, Language and Hearing Research, 49, 278-294.

Catts, H. W., Compton, D., Tomblin, J. B., \& Bridges, M. S. (2012). Prevalence and nature of late-emerging poor readers. Journal of Educational Psychology, 104, 166-181.

Catts, H., Fey, M., Zhang, X., \& Tomblin, J. (2001). Estimating the risk of future reading difficulties in kindergarten children: A research-based model and its clinical implementation. Language, Speech, and Hearing Services in School, 32, 38-50.

Catts H., Hogan T., Adolf S. (2005). Developmental changes in reading and reading disabilities. In H. Catts \& A. Kamhi (Eds.), Connections between language and reading disabilities (pp. 2540). Mahwah, NJ: Erlbaum.

Catts, H. W., Hogan, T. P., \& Fey, M. E. (2003). Subgrouping poor readers on the basis of individual differences in reading-related abilities. Journal of Learning Disabilities, 36, 151-164.

Chafe, W. \& Danielewicz, J. (1987). Properties of spoken and written language. In R. Horowitz \& S. Samuels (Eds.), Comprehending 
oral and written language (pp. 83-113). New York: Academic Press.

Chen, Q., Knok, O., Luo, W., \& Willson, V. L. (2010). The impact of ignoring a level of nesting structur in multilevel growth mixture models: A Monte Carlo Study. Structural Equation Modeling, 17, 570-589.

Clarke, P., Snowling, M., Truelove, E., \& Hulme, C. (2010). Ameliorating children's reading-comprehension difficulties: A randomized controlled trial. Psychological Science, 21, 11061116.

Coltheart, M., Rastle, K., Perry, C., Langdon, R., \& Ziegler, J. (2001). DRC: A dual route cascaded model of visual word recognition and reading aloud. Psychological Review, 108, 204-256.

Cornoldi, C., de Beni, R., \& Pazzaglia, F. (1996). Profiles of reading comprehension difficulties: An analysis of single cases. In C. Cornoldi \& J. Oakhill (Eds.), Reading comprehension difficulties: Processes and interventions (pp. 113-136). Mahwah, NJ: Erlbaum.

Cragg, L., \& Nation, K. (2006). Exploring written narrative in children with poor reading comprehension. Educational Psychology, 26, $55-72$.

Cutting, L. E., \& Scarborough, H. S. (2006). Prediction of reading comprehension: relative contributions of word recognition, language proficiency, and other cognitive skills can depend on how comprehension is measured. Scientific Studies of Reading, 10, 277-299.

Daneman, M., \& Carpenter, P.A. (1980). Individual differences in working memory and reading. Journal of Verbal Learning \& Verbal Behavior, 19, 450-466.

de Beni, R., Palladino, P., Pazzaglia, F., \& Cornoldi, C. (1998). Increases in intrusion errors and working memory deficits of poor comprehenders. Quarterly Journal of Experimental Psychology: Human Experimental Psychology, 51A, 305-320.

de Jong, P. F., \& Olson, R. K. (2004). Early predictors of letter knowledge. Journal of Experimental Child Psychology, 88, 254273.

de Jong, P. F., \& van der Leij, A. (1999). Specific contributions of phonological abilities to early reading acquisition: Results from a Dutch latent variable longitudinal study. Journal of Educational Psychology, 91, 450-476. 
de Jong, P., \& van der Leij, A. (2002). Effects of phonological abilities and linguistic comprehension on the development of reading. Scientific Studies of Reading, 6, 37-41.

de Jong, P. F., \& van der Leij, A. (2003). Developmental changes in the manifestation of a phonological deficit in dyslexic children learning to read a regular orthography. Journal of Educational Psychology, 95, 22-40.

de Jong, P. F., \& Vrielink, L. O. (2004). Rapid automatic naming: Easy to measure, hard to improve (quickly). Annals of Dyslexia, $54,65-88$.

Denkla, M. B., \& Rudel. R. G. (1974a). Rapid “automatized" naming (RAN): Dyslexia differentiated form other learning disabilities. Neuropsychologia, 14, 471-479.

Denkla, M. B., \& Rudel. R. G. (1974b). Rapid "automatized" naming of picture objects, objects, colors, letter and numbers by normal children. Cortex, 10, 186-202.

Ehri, L. (1989). The development of spelling knowledge and its role in reading acquisition and reading disability. Journal of Learning Disabilities, 22, 356-465.

Ehri, L. (1991). Development of the ability to read words. In R. Barr, M. Kamil, P. Mosenthal, \& P. Pearson (Eds.), Handbook of reading research Volume II (pp. 383-417). New York: Longman.

Ehri, L. C. (2005). Learning to Read Words: Theory, Findings, and Issues. Scientific Studies of Reading, 9, 167-188.

Ehri, L. C., Nunes, S. R., Stahl, S. A., \& Willows, D. M. (2001). Systematic phonics instruction helps students learn to read: Evidence from the National Reading Panel's meta-analysis. Review of Educational Research, 71, 393-447.

Ehri, L., \& Wilce, L. (1979). The mnemonic value of orthography among beginning readers. Journal of Educational Psychology, 71, 26-40.

Ehri, L., \& Wilce, L. (1985). Movement into reading: Is the first stage of printed word learning visual or phonetic? Reading Research Quarterly, 20, 163-179.

Elbro, C., Borstrøm, I., \& Petersen, D. (1998). Predicting dyslexia from kindergarten: The importance of distinctness of phonological representations of lexical items. Reading Research Quarterly, 33, $36-60$. 
Elbro, C., \& Buch-Iversen, I. (2013). Activation of background knowledge for inference making: Effects on reading comprehension. Scientific Studies of Reading, 17, 435-452.

Elleman, A. M., Lindo, E. J., Morphy, P., \& Compton, D. L. (2009). The impact of vocabulary instruction on passage-level comprehension of school-age children: A meta-analysis. Journal of Research on Educational Effectiveness, 2, 1-44.

Farnia, F., \& Geva, E. (2013). Growth and predictors of change in English language learners' reading comprehension. Journal of Research in Reading, 36, 389-421.

Florit, E., \& Cain, K. (2011). The Simple View of Reading: Is it valid for different types of alphabetic orthographies? Educational Psychology Review, 23, 553-576.

Francis, D. J., Fletcher, J. M., Catts, H., \& Tomblin, J. B. (2005). Dimensions affecting the assement of reading comprehension. In S. G. Paris \& S. A. Stahl (Eds.), Children's reading comprehension and assessment (pp. 369-394). Mahwah, NJ: Erlbaum.

Frost, J., Madsbjerg, S., Niedersøe, J., Olofsson, A., \& Sørensen, P. M. (2005). Semantic and phonological skills in predicting reading development: from 3-16 years of age. Dyslexia, 11, 79-92.

Furnes, B., \& Samuelsson, S. (2009). Preschool cognitive and language skills predicting Kindergarten and Grade 1 reading and spelling: A cross-linguistic comparison. Journal of Research in Reading, 32, 275-292.

Furnes, B., \& Samuelsson, S. (2010). Predicting reading and spelling difficulties in transparent and opaque orthographies: A comparison between Scandinavian and US/Australian children. Dyslexia, 16, 119-142.

Furnes, B., \& Samuelsson, S. (2011). Phonological awareness and rapid automatized naming predicting early development in reading and spelling: Results from a cross-linguistic longitudinal study. Learning and Individual Differences, 21, 85-95.

Gathercole, S., Willis, C., Emslie, H., \& Baddeley, A. D. (1992). Phonological memory and vocabulary development during the early school years: A longitudinal study. Developmental Psychology, 28, 887-898.

Gernsbacher, M. A. (1990). Language comprehension as structure building. Hillsdale, NJ: Erlbaum. 
Goodman, K. (1970). Behind the eye: What happens in reading. In K. Goodman \& O. Niles (Eds.), Reading: Process and program (pp. 3-38). Urbana, IL: National Council of Teachers of English.

Goswami, U. (1986). Children's use of analogy in learning to read: A developmental study. Journal of Psycholinguistic Research, 4, 331-342.

Goswami, U., \& Bryant, P. E. (1990). Phonological skills and learning to read. Hillsdale, NJ: Erlbaum.

Gough P. B., Hoover W. A., Peterson C. (1996). Some observations on the simple view of reading. In C. Cornoldi, \& J. Oakhill (Eds.), Reading comprehension difficulties. Hillsdale, NJ: Erlbaum.

Gough, P., \& Tunmer, W. (1986). Decoding, reading and reading disability. Remedial and Special Education, 7, 6-10.

Graesser, A. C., Singer, M., \& Trabasso, T. (1994). Constructing inferences during narrative text comprehension. Psychological Review, 101, 371-395.

Griffiths, Y. M., \& Snowling, M. J. (2002). Predictors of exception word and non-word reading in dyslexic children: The severity hypothesis. Journal of Educational Psychology, 94, 34-43.

Guthrie, J. T., Wigfield, A., Barbosa, P., Perencevich, K. C., Taboada, A., Davis, M. H., ... Tonks, S. (2004). Increasing reading comprehension and engagement through concept-oriented reading instruction. Journal of Educational Psychology, 96, 403-423.

Hart, B., \& Risley, T. (2003). The early catastrophe: The 30 million word gap. American Education, 27, 4-9.

Hoover, W., \& Gough, P. B. (1990). The simple view of reading. Reading and Writing, 2, 127-160.

Hulme, C., \& Snowling, M. J. (2011). Children's reading comprehension difficulties: Nature, causes, and treatments. Current Directions in Psychological Science, 20, 139-142.

Johnson-Laird, P. N. (1983). Mental models. Cambridge, England: Cambridge University Press.

Justice, L., Mashburn, A., \& Petscher, Y. (2013). Very early language skills of fifth-grade poor comprehenders. Journal of Research in Reading, 36, 172-185.

Kahmi, A. G., \& Catts, H. W. (2012). Language and reading: Convergences and divergences. In A .G. Kahmi \& H. W. Catts (Eds.), Language and reading disabilities (3rd ed.) (pp. 1-23). Boston: Pearson. 
Kail, R., Hall, L. K., \& Caskey, B. J. (1999). Processing speed, exposure to print, and naming speed. Applied Psycholinguistics, 20, 303-314.

Keenan, J. M., \& Betjemann, R. S. (2006). Comprehending the Gray Oral Reading Test without reading it: Why comprehension test should not include passage-independent items. Scientific Studies of Reading, 12, 281-300.

Keenan, J. M., Betjemann, R. S., \& Olson, R. K. (2008). Reading comprehension tests vary in the skills they assess: Differential dependence on decoding and oral comprehension. Scientific Studies of Reading, 12, 281-300.

Keenan, J., \& Meenan, C. E. (2014). Test differences in diagnosing reading comprehension deficits. Journal of Learning Disabilities, 47, 125-135

Kendeou, P., van den Broek, P., White, M. J., \& Lynch, J. S. (2009). Predicting reading comprehension in early elementary school: The independent contributions of oral language and decoding skills. Journal of Educational Psychology, 101, 765-778.

Kintsch, W. (1998). Comprehension: A paradigm for cognition. New York: Cambridge University Press.

Kintsch, W. \& Rawson, K. A. (2005). Comprehension. In M. J. Snowling \& C. Hulme (Eds.), The Science of Reading: A handbook (pp. 211-226). Oxford, UK: Blackwell.

Kintsch, W., \& van Dijk, T. A. (1978). Toward a model of text comprehension and production. Psychological Review, 85, 363394.

Kirby, J. R., \& Savage, R. S. (2008). Can the simple view deal with the complexities of reading? Literacy, 42, 75-82.

Kirby, J. R., Silvestri, R., Allingham, B. H., Parrila, R., \& La Fave, C. B. (2008). Learning strategies and study approaches of postsecondary students with dyslexia. Journal of Learning Disabilities, 41, 85-96.

Kolb B., Wishaw I. Q. (2009). Fundamentals of human neuropsychology. New York: Worth Publishers

Landerl, K., \& Wimmer, H. (2000). Deficits in phoneme segmentation are not the core problem of dyslexia: Evidence from German and English children. Applied Psycholinguistics, 21, 243-262. 
Leach, J. M., Scarborough, H. S., \& Rescorla, L. (2003). Lateemerging reading disabilities. Journal of Educational Psychology, 95, 201-224.

Lervåg, A., \& Hulme, C. (2009). Rapid automatized naming (RAN) taps a mechanism that places constraints on the development of early reading fluency. Psychological Science, 20, 1040-1048.

Liberman, I., Shankweiler, D., Fischer, F., \& Carter, B. (1974). Explicit syllable and phoneme segmentation in the young child. Journal of Experimental Child Psychology, 18, 201-212.

Livingstone, M., Rosen, G., Drislane, F \& Galaburda, A. (1991). Physiological and anatomical evidence for a magnocellular defect in developmental dyslexia. Proceeding of the National Academy of Science, 88, 7943- 7947.

Lonigan, C., Burgess, S., \& Anthony, J. (2000). Development of emergent literacy and early reading skills in preschool children: Evidence from a latent-variable longitudinal study. Developmental Psychology, 36, 596-613.

Lovegrove, W. J., Bowling, A., Badcock, B., Blackwood, M. (1980). Specific reading disability: Differences in contrast sensitivity as a function of spatial frequency. Science, 210, 439-440.

Lundberg, I., Frost, J., \& Petersen, O. P. (1998). Effects of an extensive program for stimulating phonological awareness in preschool children. Reading Research Quarterly, 23, 263-284.

Lyon, G. R., Shaywitz, S. E., \& Shaywitz, B. A. (2003). A definition of dyslexia. Annals of Dyslexia, 53. 1-14.

Lyytinen, H., Erskine, J., Tolvanen, A, Torppa, M., Poikkeus, A., \& Lyytinen, P. (2006). Trajectories of reading development: A follow-up from birth to school age of children with and without risk for dyslexia. Merrill-Palmer Quarterly, 52, 514-547.

MacGinitie W. E., \& MacGinitie, R. K. (1989). Gates-MacGinitie Reading Tests. Chicago: Riverside Publishing Company.

Mandler, J. M. (1984). Stories, scripts, and scenes: Aspects of schema theory. Hillsdale NJ: Erlbaum.

Mann, V., \& Wimmer, H. (2002). Phoneme awareness and pathways into literacy: A comparison of German and American children. Reading and Writing, 15, 653-682.

Masonheimer, P. E., Drum, P. A., \& Ehri, L. C. (1984). Does environmental print identification lead children into word reading? Journal of Reading Behavior, 16, 257-271. 
McCarthy, J. J. \& Kirk, C. A. (1961). The Illinois Test of Psycholinguistic Abilities. Urbana, IL: University of Illinois Press. McKeown, M. G., Beck, I. L., Omanson, R. C., \& Perfetti, C. A. (1983). The effects of long-term vocabulary instruction on reading comprehension: A replication. Journal of Reading Behavior, 15, 3-18.

Melby-Lervåg, M., Lervåg, A., Lyster, S-A. H., Klem, M., Hagtvet, B., \& Hulme, C. (2012). Non-word-repetition ability does not appear to be a causal influence on children's vocabulary development. Psychological Science, 23, 1092-1098.

Melby-Lervåg, M., Lyster, S-A. H., \& Hulme, C. (2012). Phonological skills and their role in learning to read: A meta-analytic review. Psychological Bulletin, 138, 322-352.

Metsala, J. L., \& Walley, A. C. (1998). Spoken vocabulary growth and the segmental restructuring of lexical representations: Precursors to phonemic awareness and early reading ability. In J. L. Metsala \& L. C. Ehri (Eds.), Word recognition in beginning literacy (pp. 89-120). Mahwah, New Jersey: Erlbaum.

Muter, V., Hulme, C., Snowling, M. J., \& Stevenson, J. (2004). Phonemes, rimes, vocabulary, and grammatical skills as foundations of early reading development: Evidence from a longitudinal study. Developmental Psychology, 40, 665-81.

National Reading Panel. (2000). Teaching children to read: An evidence-based assessment of the scientific research literature on reading and its implication for reading instruction. Washington, DC: National Institute for Child and Human Development.

Nation, K. (2005). Children's reading comprehension difficulties. In M. J. Snowling \& C. Hulme (Eds.), The science of reading: A handbook (pp. 248-266). Oxford, UK: Blackwell.

Nation, K., Adams, J. W., Bowyer-Crane, C. A, \& Snowling, M. J. (1999). Working memory deficits in poor comprehenders reflect underlying language impairments. Journal of Experimental Child Psychology, 73, 139-58.

Nation, K., \& Clarke, P., Marshall, C. M., \& Durand, M. (2004). Hidden language impairment in children: Parallels between poor reading comprehension and SLI? Journal of Speech, Language and Hearing Research, 47, (199-212.

Nation, K., Cocksey, J., Taylor, J. S. H., \& Bishop, D. V. M. (2010). A longitudinal investigation of early reading and language skills in 
children with poor reading comprehension. Journal of Child Psychology and Psychiatry, 51, 1031-1039.

Nation, K., \& Snowling, M. (1997). Assessing reading difficulties: The validity and utility of current measures of reading skill. The British Journal of Educational Psychology, 67, 59-70.

Nation, K., \& Snowling, M. J. (1998a). Individual differences in contextual facilitation: Evidence from dyslexia and poor reading comprehension. Child Development, 69, 996-1011.

Nation, K. \& Snowling, M. (1998b). Semantic processing and the development of word recognition skills: Evidence from children with reading comprehension difficulties. Journal of Memory and Language, 39, 85-101.

Nation, K., Snowling., M. J., \& Clarke, P.(2005). Production of the English past tense by children with language comprehension impairment. Journal of Child Language, 32, 117-137.

Neale, M. D. (1997). The Neale Analysis of Reading Ability - Revised. Windsor: NFER-Nelson.

Neale, M. C., \& Cardon, L. R. (1992). Methodology for genetic studies of twins and families. Dordrecht, the Netherlands: Kluwer Academic .

Nicolson, R. I., \& Fawcett, A. J. (1990). Automaticity: A new framework for dyslexia research? Cognition, 35, 159-182.

Nicolson, R., Facett, A. J., Dean, P. (2001). Dyslexia, development and the cerebellum. Trends in Neuroscience, 24, 515-516.

Norton, E. S., \& Wolf, M. (2012). Rapid automatized naming (RAN) and reading fluency: implications for understanding and treatment of reading disabilities. Annual Review of Psychology, 63, 427-52.

Olson, R. K., Keenan, J. M., Byrne, B., Samuelsson, S., Coventry, W. L., Corley, R.,...Hulslander, J. (2011). Genetic and environmental influences on vocabulary and reading development. Scientific Studies of Reading, 15, 26-46.

Ouellette, G. P. (2006). What's meaning got to do with it: The role of vocabulary in word reading and reading comprehension. Journal of Educational Psychology, 98, 554-566.

Ouellette, G., \& Beers, A. (2009). A not-so-simple view of reading: How oral vocabulary and visual-word recognition complicate the story. Reading and Writing, 23, 189-208. 
Palinscar, A. S., \& Brown, A. L. (1984). Reciprocal teaching of comprehension-fostering and comprehension monitoring activities. Cognition and Instruction, 2, 117-175.

Papadopoulos, T. C., Georgiou, G. K., \& Kendeou, P. (2009). Investigating the double-deficit hypothesis in Greek: Findings from a longitudinal study. Journal of Learning Disabilities, 42, $528-547$.

Parrila, R., Kirby, J., \& McQuarrie, L. (2004). Articulation rate, naming speed, verbal short-term memory, and phonological awareness: Longitudinal predictors of early reading development? Scientific Studies of Reading, 8, 3-26.

Perfetti, C.A. (1985). Reading ability. New York: Oxford U.P.

Perfetti, C. A., Beck, I., Bell, L., \& Hughes, C. (1987). Phonemic knowledge and learning to read are reciprocal: A longitudinal study of first grade children. Merrill-Palmer Quarterly, 33, 283319.

Perfetti, C. A., Marron, M. A. , \& Foltz, P. W. (1996). Sources of comprehension failure: Theoretical perspectives and case studies. In C. Cornoldi \& J. V. Oakhill (Eds.), Reading comprehension difficulties: Processes and remediation (pp. 137-165). Mahwah, NJ: Erlbaum.

Powell, D., Stainthorp, R., Stuart, M., Garwood, H., \& Quinlan, P. (2007). An experimental comparison between rival theories of rapid automatized naming performance and its relationship to reading. Journal of Experimental Child Psychology, 98, 46-68.

Preacher, K. J., Rucker, D. D., MacCallum, R. C., \& Nicewander, W. A. (2005). Use of the extreme groups approach: A critical reexamination and new recommendations. Psychological Methods, 10, 178-92.

Pressley, M. (2006). Reading instruction that works: The case for balanced teaching (3rd ed). New York: The Guildford Press.

Ramus, F., Rosen, S., Dakin, S. C., Day, B. L., Castellote, J. M., \& White, S. (2003). Theories of developmental dyslexia: Insights from a multiple case study of dyslexic adults. Brain, 126, 841865.

Rego, L. L. B., \& Bryant, P. E. (1993). The connection between phonological, syntactic and semantic skills and children's reading and spelling. European Journal of Psychology and Education, 8, 235-246. 
Ricketts, J., Nation, K., \& Bishop, D. V. M. ( 2007). Vocabulary is important for some, but not all reading skills. Scientific Studies of Reading, 11, 235-257.

Roth, F. P., Speece, D. L., \& Cooper, D. H. (2002). A longitudinal analysis of the connection between oral language and early reading. The Journal of Educational Research, 95, 259-272.

Samuelsson, S., Byrne, B., Quain, P., Wadsworth, S., Corley, R., DeFries, J. C., ... Olson, R. (2005). Environmental and genetic influences on prereading skills in Australia, Scandinavia, and the United States. Journal of Educational Psychology, 97, 705-722.

Scarbourough, H. (1998). Early identification of children at risk for reading disabilities phonological awareness and some other promising predictors. In B. K. Shapiro, P. J. Accardo, \& A. J. Capute (Eds.), Specific reading disability: A view of the spectrum (pp. 75-119). Trinonium, MD: York Press.

Scarborough, H. S., \& Parker, J. D. (2003). Children's learning and teachers expectations: Matthew effects in children with learning disabilities: Development of reading, IQ and psychosocial problems from grade 2 to grade 8. Annals of Dyslexia, 53, 47-71.

Schatschneider, C., \& Carlson, C. (2002). Relationship of rapid automatized naming and phonological awareness in early reading development: Implications for the double-deficit hypothesis. Journal of Learning Disabilities, 35, 245-256.

Schatschneider, C., Fletcher, J. M., Francis, D. J., Carlson, C. D., \& Foorman, B. R. (2004). Kindergarten prediction of reading skills: A longitudinal comparative analysis. Journal of Educational Psychology, 96, 265-282.

Seigneuric, A., Ehrlisch, M., Oakhill, J. V. \& Yuill, N. Y. (2000). Working memory resources and children's reading comprehension. Reading \& Writing, 13, 81-103.

Sénéchal, M., Ouellette, G., \& Rodney, D. ( 2006). The misunderstood giant: The predictive role of early vocabulary to future reading. In D. K. Dickinson \& B. S. Neuman (Eds.), Handbook of early literacy (vol. 2) (pp. 173-185). New York, NY: Guildford.

Shapiro, L. R., Carroll, J. M., \& Solity, J. E. (2013). Separating the influences of prereading skills on early word and non-word reading. Journal of Experimental Child Psychology, 116, 278295. 
Share, D. L. (1995). Phonological recoding and self-teaching: Sine qua non of reading acquisition. Cognition, 55, 151-218.

Snowling, M. J. (2000). Dyslexia (2nd ed.). Blackwell Publishers, Oxford. U.K.

Snowling, M. J., Stackhouse, J., \& Rack, J. P. (1986). Phonological dyslexia and dysgraphia: A developmental analysis. Cognitive Neuropsychology, 3, 309-339.

Speece, D. L., Roth, F. P., Cooper, D. H., \& de la Paz, S. (1999). The relevance of oral language skills to early literacy: A multivariate analysis. Applied Psycholinguistics, 20, 167-190.

Spooner, A. L. R., Baddeley, A. D., \& Gathercole, S. E. (2004). Can reading accuracy and comprehension be separated in the Neale Analysis of Reading Ability? The British Journal of Educational Psychology, 74. 187-204.

Stahl, S. A., \& Fairbanks, M. M. (1986). The effects of vocabulary instruction: A model-based meta-analysis. Review of Educational Research, 56, 72-110.

Stanovich, K. E. (1986). Matthew effects in reading: Some consequences of individual differences in the acquisition of literacy. Reading Research Quarterly, 21, 360-406.

Stanovich, K. E. (1988). Explaining the differences between the dyslexic and garden variety poor reader - the phonological corevariable-difference model. Journal of Learning Disabilities, 21, 590-604.

Stanovich, K. E., Cunningham, A. E., \& Freeman, D. J. (1984). Intelligence, cognitive skills, and early reading progress. Reading Research Quarterly, 19, 278-303

Stanovich, K., \& Siegel, L. (1994). Phenotypic performance profile of children with reading disabilities: A regression-based test of the phonological-core variable-difference model. Journal of Educational Psychology, 86, 24-53.

Storch, S. A, \& Whitehurst, G. J. (2002). Oral language and coderelated precursors to reading: Evidence from a longitudinal structural model. Developmental Psychology, 38, 934-947.

Stothard, S. E. \& Hulme, C. (1992). Reading comprehension difficulties in children: The role of language comprehension and working memory skills. Reading \& Writing, 4, 245-256.

Stuart, M., \& Coltheart, M. (1988). Does reading develop in a sequence of stages? Cognition, 30, 139-181. 
Swanson, H. L., \& Alexander, J. E. (1997). Cognitive processes as predictors of word recognition and reading comprehension in learning disabled and skilled readers: Revisiting the specificity hypothesis. Journal of Educational Psychology, 89, 128-158.

Swanson, H. L., \& Siegel, L. (2001). Learning disabilities as a working memory deficit. Issues in Education: Contributions of Educational Psychology, 7, 1-48.

Tallal, P. (1980). Auditory temporal perception, phonics, and reading disabilities in children. Brain Language, 9, 182-198.

Tallal , P. Miller, S., \& Fitch R. H. (1993). Neurobiological basis of speech: A case for the preeminence of temporal processing. Annuals of the New York Academy of Sciences, 682, 27-47.

Tarchi, C. (2010). Reading comprehension of informative texts in secondary school: A focus on direct and indirect effects of reader's prior knowledge. Learning and Individual Differences, 20, 415-420.

Tong, X., Deacon, S. H., Kirby, J. R., Cain, K., \& Parrila, R. (2011). Morphological awareness: A key to understanding poor reading comprehension in English. Journal of Educational Psychology, $103,523-534$.

Torgesen, J. K., Wagner, R. K., Rashotte, C. A., Burgess, S., \& Hecht, S. (1997). Contributions of phonological awareness and rapid automatic naming ability to the growth of word-reading skills in second-to fifth-grade children. Scientific Studies of Reading, 1, $37-41$.

Torgesen, J. K., Wagner, R. K., \& Rashotte, C. A. (1999). Test of Word Reading Efficiency. Austin, TX: Pro-ed.

Torppa, M., Georgiou, G., Salmi, P., Eklund, K., \& Lyytinen, H. (2012). Examining the double-deficit hypothesis in an orthographically consistent language. Scientific Studies of Reading, 16, 287-315.

Torppa, M., Lyytinen, P., Erskine, J., Eklund, K., \& Lyytinen, H. (2010). Language development, literacy skills, and predictive connections to reading in Finnish children with and without familial risk for dyslexia. Journal of Learning Disabilities, 43, 308-321.

Torppa, M., Tolvanen, A., Poikkeus, A.-M., Eklund, K., Lerkkanen, M.-K., Leskinen, E., \& Lyytinen, H. (2007). Reading development 
subtypes and their early characteristics. Annals of Dyslexia, 57, $3-$ 32.

Tunmer, W. E., \& Chapman, J. W., (1998). Language prediction skill, phonological recoding ability and beginning reading. In $\mathrm{C}$. $\mathrm{H}$. Hulme \& R. M. Joshi (Eds.), Reading and Spelling: Development and disorder (pp. 33-67). Mahwah, NJ: Erlbaum.

Vellutino, F. R., Fletcher, J. M., Snowling, M., \& Scanlon, D. (2004). Specific reading disability (dyslexia): What have we learned in the past four decades? Journal of Child Psychology and Psychiatry, $45,2-40$.

Vellutino, F. R., Tunmer, W. E., Jaccard, J. J., \& Chen, R. (2007). Components of reading ability: Multivariate evidence for a convergent skill model of reading development. Scientific Studies of Reading, 11, 3-32.

Vukovic, R. K., \& Siegel, L. S. (2006). The double-deficit hypothesis: A comprehensive analysis of the evidence. Journal of Learning Disabilities, 39, 25-47.

Wagner, R. K., \& Torgesen, J. K. (1987). The nature of phonological processing and its causal role in the acquisition of reading skills. Psychological Bulletin, 101, 192-212.

Wagner, R. K., Torgesen, J. K., \& Rashotte, C.A. (1994). Development of reading-related phonological processing abilities: New evidence of bidirectional causality from a latent variable longitudinal study. Developmental Psychology, 30, 73-87.

Wagner, R. K., Torgesen, J. K., Rashotte, C. A, Hecht, S. A, Barker, T. A, Burgess, S. R., ...Garon, T. (1997). Changing relations between phonological processing abilities and word-level reading as children develop from beginning to skilled readers: A 5-year longitudinal study. Developmental Psychology, 33, 468-479.

Wechsler, D. (1989). Manual for the Wechsler Preschool and Primary Scale of Intelligence-Revised. New York: Psychological Corporation.

Westby, C. C. (2012). Assessing and remediating text comprehension problems. In A. G. Kahmi \& H. W. Catts (Eds.), Language and Reading Disabilities (3rd ed.) (pp. 163-225). Boston: Pearson.

Westlund, B. (2009). Att undervisa i läsförståelse: Lässtrategier och studieteknik för de första skolåren. Stockholm: Natur \& kultur. 
Wolf, M., \& Bowers, P. (1999). The double-deficit hypothesis for the developmental dyslexias. Journal of Educational Psychology, 91, 415-438.

Wolter, J. A., Wood, A. \& D'zatko, K. W. (2009). The influence of morphological awareness on the literacy development of firstgrade children. Language, Speech and Hearing Services in Schools, 40, 286-298.

Woodcock, R. (1987). Woodcock Reading Mastery Tests- Revised. Circle Pines MN: American Guidance Service.

Yuill, N., \& Oakhill, J. (1991). Children's problems in text comprehension. Cambridge: Cambridge University Press.

Yuill, N., Oakhill, J. \& Parkin, A. (1989). Working memory, comprehension ability and the resolution of text anomaly. British Journal of Psychology, 80, 351-361.

Zwiers, J. (2008). Building academic language: Essential practices for content classrooms, grades 5-12. San Francisco, Calif.: JosseyBass. 


\section{Papers}

The articles associated with this thesis have been removed for copyright reasons. For more details about these see:

http://urn.kb.se/resolve?urn=urn:nbn:se:liu:diva-110036 

158. BIRBERG THORNBERG, ULRIKA. Fats in Mind. Effects of Omega-3 Fatty Acids on Cognition and Behaviour in Childhood. 2011. ISBN: 978-917393- 164-9

159. KILHAMMAR, KARIN. Idén om medarbetarskap. En studie av en idés resa in i och genom två organisationer. 2011. ISBN: 978-91-7393-092-05

160. SARKOHI, ALI. Future Thinking and Depression. 2011. ISBN: 978-917393-020-8

161. LECH, BÖRJE. Consciousness about own and others’ affects. 2012. ISBN: 978-91-7519-936-8

162. JOHNSON FRANKENBERG, SOFIA. Caregiving Dilemmas: Ideology and Social Interaction in Tanzanian Family Life. 2012. ISBN: 978-91-7519908-5

163. HALLQVIST, ANDERS. Work Transitions as Biographical Learning. Exploring the dynamics of job loss. 2012. ISBN: 978-91-7519-895-8

164. MUHIRWE, CHARLES KARORO. Developing Academic Literacies in Times of Change. Scaffolding Literacies Acquisition with the Curriculum and ICT in Rwandan Tertiary Education. 2012. ISBN: 978-91-7519-841-5

165. RUTERANA, PIERRE CANISIUS. The Making of a Reading Society. Developing a Culture of Reading in Rwanda. 2012. ISBN: 978-91-7519840-8

166. SANDBERG, FREDRIK. Recognition of Prior Learning in Health Care. From a Caring Ideology and Power, to Communicative Action and Recognition. 2012. ISBN: 978-91-7519-814-9

167. FÄGERSTAM, EMILIA. Space and Place. Perspectives on Outdoor Teaching and Learning. 2012. ISBN: 978-91-7519-813-2

168. FALKENSTRÖM, FREDRIK. The Capacity for Self-Observation in Psychotherapy. 2012. ISBN: 978-91-7519-797-5

169. BENNICH, MARIA. Kompetens och kompetensutveckling i omsorgsarbete. Synen på kompetens och lärande i äldreomsorgen - i spänningsfältet mellan samhälleliga förutsättningar och organisatoriska villkor. 2012. ISBN: 978-91-7519-777-7

170. RUSANGANWA, JOSEPH. Enhancing Physics Learning through Instruction, Technical Vocabulary and ICT. A Case of Higher Education in Rwanda. 2012. ISBN: 978-91-7519-739-5

171. MBABAZI, PENELOPE. Quality in Learning in Rwandan Higher Education: Different Stakeholders' Perceptions of Students' Learning and Employability. 2013. ISBN: 978-91-7519-682-4 
172. BYSTRÖM, ERICA. Ett lärorikt arbete? Möjligheter och hinder för undersköterskor att lära och utvecklas i sjukvårdsarbetet. 2013. ISBN:978-917519-679-4

173. KAGWESAGE, ANNE MARIE. Coping with Learning through a Foreign Language in Higher Education in Rwanda. 2013. ISBN: 978-91-7519-6404

174. MUTWARASIBO, FAUSTIN. Understanding Group-based Learning in an Academic Context: Rwandan Students' Reflections on Collaborative Writing and Peer Assessment. 2013. ISBN: 978-91-7519-633-6

175. MÅRDH, SELINA. Cognitive erosion and its implications in Alzheimer's disease. 2013. ISBN: 978-91-7519-612-1

176. HARLIN, EVA-MARIE. Lärares reflektion och professionella utveckling Med video som verktyg. 2013. ISBN: 978-91-7519-611-4

177. ÖSTERGREN, RICKARD. Mathematical Learning Disability. Cognitive Conditions, Development and Predictions. 2013. ISBN: 978-91-7519-565-0

178. ENGVALL, MARGARETA. Handlingar i matematikklassrumet. En studie av undervisningsverksamheter på lågstadiet då räknemetoder för addition och subtraktion är i fokus. 2013. ISBN: 978-91-7519-493-6

179. JOHANSSON, ROBERT. Treating depression and its comorbidity. From individualized Internet-delivered cognitive behavior therapy to affectfocused psychodynamic psychotherapy. 2013. ISBN: 978-91-7519-467-7

180. BERGMAN NORDGREN, LISE. Individually tailored internet-based cognitive behavioural therapy for anxiety disorders. 2013. ISBN: 978-917519-459-2

181. FREJD, PETER. Modes of Mathematical Modelling. An Analysis of how modelling is used and interpreted in and out of school settings. 2014. ISBN: 978-91-7519-414-1

182. AMAN, ROBERT. Impossible Interculturality? Education and the Colonial Difference in a Multicultural World. 2014. ISBN: 978-91-7519-348-9

183. NYLANDER, ERIK. Skolning i jazz. Värde, selektion och studiekarriär vid folkhögskolornas musiklinjer. 2014. ISBN: 978-91-7519-347-2

184. GRADIN FRANZÈN, ANNA. Disciplining freedom: Treatment dilemmas and subjectivity at a detention home for young men. 2014. ISBN: 978-917519-344-1

185. ENGSTRÖM, ANNIKA. Lärande samspel för effektivitet. En studie av arbetsgrupper i ett mindre industriföretag. 2014. ISBN:978-91-7519-345-8 